\title{
Size and Liquidity Effects in Japanese regional stock markets
}

\author{
Bruce Hearn* \\ King's College London
}

\begin{abstract}
This paper assesses the effectiveness of traded turnover, Amihud (2002) and Liu (2006) metrics in measuring illiquidity, as used in a multifactor CAPM. The performance of this model is contrasted using a unique sample from Japan's regional stock exchanges, namely Sapporo, Nagoya, Fukuoka, Osaka and Tokyo. The evidence suggests that size effects are important in Tokyo, liquidity plays a more important role in the conditional modelling of returns particularly in the smaller markets of Sapporo, Fukuoka and Nagoya where costs of equity are highest.
\end{abstract}

JEL classification: G11, G12, G15, O55

Keywords: Liquidity, Portfolio Diversification, Regional Financial Markets, Japan

Corresponding author: School of Management, University of Leicester, Ken Edwards Building, Leicester. UK. LE1 7RH. Tel: 44(0)116 252 5520. Email: bruce.hearn@kcl.ac.uk 


\section{Size and Liquidity Effects in Japanese regional stock markets}

\section{INTRODUCTION}

The application of standard asset pricing theory dictates that the cross-section of expected stock returns are related to returns sensitivities to state variables that are themselves linked to investors overall welfare (Pastor and Stambaugh, 2003). Assets whose lowest returns accompany unfavourable shifts in that welfare must compensate investors for the loss of value while holding the asset. While Fama and French (1993) proposed that variations in size as well as differences between accounting book to market value of stocks across a universe of stocks as state variables there is considerable recent evidence that liquidity is also such a state variable (Liu, 2006; Pastor and Stambaugh, 2003) that must be accounted for in pricing models. The presence of size effects is especially likely within smaller regional stock markets where the majority of listings arise either from occasional listings of larger internationally focussed firms or from indigenous small and medium enterprises (SMEs) that play an active role in the localised regional political economy (Choe, 2007). This dispersion in types of firm listing is also likely to lead to considerable differences between value and growth stocks generating a book-to-market effect (Fama and French, 1993). The presence of this in Tokyo stock exchange data is well documented (Chan et al, 1991; Daniel et al, 2001). Additionally there are also likely to be large differences in liquidity between firms within and between markets (Pastor and Stambaugh, 2003) which has also recently been documented in Tokyo stock exchange data (Chang et al, 2010). Consequently this empirical study investigates whether size, book to market value and liquidity effects are priced. As such I ask whether differences in cross sectional expected returns can be better explained by fluctuations in aggregate market size and liquidity effects as opposed to size and book to market factors alone.

Liquidity as a concept is very hard to define largely because its representative characteristics transcend a number of transactional properties of markets including tightness, depth, resiliency (Lesmond, 2005) and information (O’Hara, 2003). The literature has traditionally been limited in only employing constructs capturing only one dimension of a multidimensional phenomenon. This typically centres on variants of the bid-ask spread (quoted or effective) in Amihud and Mendelsen (1986), the turnover measure of Datar et al. (1998), or measures relating to the price impact arising from traded volume such as Amihud (2002) and Pastor and Stambaugh (2003). However there is very little published research concerning measures capturing the trading speed dimension of liquidity, defined as the ability to transact large quantities quickly with little price impact (Liu, 2006; Pastor and Stambaugh, 2003). Furthermore there are serious concerns over existing one-dimensional constructs ability to fully capture liquidity risk and over their inaccurate estimation of the dimension they are intended to model (Pastor and Stambaugh, 2003; Amihud, 2002). Equally deficiencies in the application of the bid-ask spread construct have been 
highlighted in Lee (1993) where evidence reveals that many large trades occur outside the bid-ask spread while many small trades are undertaken within it leading to potential bias. Further concerns over the application of one-dimensional measures focus on their being undefined in the presence of extremes of illiquidity as is a frequent occurrence in smaller regional markets (Lesmond, 2005). A more recent measure developed in Liu (2006) captures the trading speed dimension of liquidity which is defined as the standardized turnover-adjusted number of zero trading volumes over the past twelve months. It is multi-dimensional in nature, capturing effects relating to trading speed, trading quantity and trading cost, with an emphasis on trading speed, outlined as the continuity of trading and the potential delay in executing an order (Liu, 2006). An additional benefit from the use of this measure arises from its measurement robustness in the presence of significant illiquidity (Liu, 2006) as is often present in smaller regional markets although this has only been studied within the context of the developed market of the New York Stock Exchange.

The literature concerning the inclusion of liquidity as a priced state variable within a valuation framework is very recent. Pastor and Stambaugh (2003) find strong evidence from US stock data that market-wide liquidity is a priced state variable and that the liquidity premium should be positive. The study applied the innovations of a price impact measure of liquidity to sort stocks within a universe into decile portfolios with the market aggregate premium being formed in the difference between returns of the highest and lowest liquidity deciles. The explanatory power arising from inclusion of the liquidity factor were studied through the contrast of a four factor capital asset pricing model (CAPM) including market, size, price-to-book value and the new liquidity factor against the Fama and French (1993) three factor model and the CAPM. Stocks with higher sensitivity to aggregate liquidity stocks compensate investors with higher expected returns. Evidence is also found that small stocks have greater sensitivities to liquidity innovations than large stocks. Pastor and Stambaugh (2003) note that intuitively it could be expected that small and illiquid stocks are those most affected by market aggregate drops in liquidity thereby precipitating investors to "flee" to assets with higher liquidity. However their findings also show that size and liquidity are not the sole determinants of liquidity betas. This finding is reinforced by the argument explaining why stocks with a high liquidity beta are not necessarily illiquid. Investor preferences when there are market aggregate falls in liquidity are also likely to focus on rival bonds markets. In order to increase portfolio holdings in bonds investors may seek to sell liquid stocks in order to save on transactions costs. Consequently in this scenario the price reaction to aggregate liquidity changes is stronger for more liquid stocks. Equally prices of liquid stocks could have greater sensitivity to aggregate liquidity shocks if such stocks are held in greater proportions within the portfolios of liquidity-conscious investors. As such Pastor and Stambaugh (2003) find little basis for liquidity betas to bear a simple relation to stock size and liquidity. Liu (2006) builds on this background in first using a new liquidity construct to estimate stock liquidity and then including this factor within a two factor augmented capital asset pricing model (CAPM). While the 
additional liquidity factor offers strong performance in explaining the cross section of US stock returns the findings are in contradiction to the earlier findings of Pastor and Stambaugh as the liquidity premium solely subsumes the documented anomalies such as size and the book-to-market effects from Fama and French (1993).

The literature regarding liquidity in Japanese financial markets is almost exclusively focussed on the Tokyo stock exchange (TSE). Much of this earlier work has a distinctive market microstructure approach and studies the exchange design factors affecting the provision of liquidity, such as the presence of exchange-designated market makers using cross sectional methods (Lehmann and Modest, 1994) and dynamic time series methods (Hamao and Hasbrouck, 1995). However extensions have been undertaken to examine the relationship between liquidity and returns with a study of the relationship between weekly short-term stock returns and the previous weeks traded volumes (Bremer and Hiraki, 1999). More recently an extensive examination of the effects of aggregate liquidity on stock returns across the first and second tiers and mothers board of the TSE is undertaken in Chang et al (2010). While this uses a range of liquidity constructs, such as the price-impact measure of Amihud (2002), trading speed metric of Liu (2006) and several volume and price-rigidity measures (relating to number of zero trading days and zero daily returns) the study is limited to assessing the level of association between these measures and control variables through correlations. The focus of the study is on the relationship between these measures, and the returns-based factor they form in each case, and stock returns having taken into account a number of standard control variables between the TSE market segments and at different times of the Japanese business cycle. A shortfall in this research is in the direct contrasting of these measures in explaining the total trading costs, defined as the bid-ask spread plus the trading commission levied by exchange for both buy and sell sides of a trade. Consequently I ask which of these measures best explains total trading costs and use the most robust construct in forming liquidity valuation factor to further assess the relationship between liquidity and stock returns.

The current Japanese system of regional financial markets owes its existence to the postWar 1949 establishment of nine (currently five) regional stock exchanges in major regional centres, although many had originally been formed much earlier to serve the financing needs of powerful localised interests within the distinctive regional political economy (Choe, 2007). However despite the importance of the local financial markets within Japan's regional economy there is little, if any research focussing on these exchanges. This motivates my focus on the Japanese regional exchanges as well as the TSE while also considering the differences between the largest top bracket of stocks and the overall market which is an obvious source of potential segmentation.

The majority of the valuation literature concerns the implementation of pricing models that assume a time invariant relationship in the systemic (market) risk of an asset. However over the last fifteen years a separate literature concerning the time varying nature of systemic risk has evolved from an increasing concerns of the violation of assumptions inherent in the linear model 
such as normality, identity and independence of stock returns (Grout and Zalewska, 2006). Pettengill et al (1995) studied the relationship between risk and return in "up" as opposed to "down" markets while Bekeart and Harvey (1995) undertook a similar study using Markovswitching regressions across a broad sample of emerging markets to examine differences between periods of integration with world market and segmentation. Brooks et al (1998) used time varying techniques based on the Kalman-filter approach and applied to Australian industry portfolios finding that these techniques produced improved in and out of sample performances than other econometric techniques. Grout and Zalewska (2006) find that the use of Kalman filter methods is preferable to Markov-switching regressions owing to their not having to define the exact point of the switch (Grout and Zalewska, 2006). Instead any changes in the time path of betas can be assessed through the study of regression results which is particularly relevant in the modelling of liquidity effects as these are prone to considerable fluctuation within emerging markets. In the light of this evidence I use time varying techniques employing the Kalman filter framework following Brooks et al (1998).

In this study I find evidence that the Amihud price-impact and multidimensional trading speed Liu measures outperform the turnover metric in explaining total trading costs across the Japanese regional exchanges. However the Amihud construct appears more robust in explaining total costs in the smaller more illiquid markets such as Sapporo while the Liu measure is preferable in the larger Osaka and Tokyo exchanges. The evidence from time series analysis of returns from portfolios of both top tier stocks and the overall market where a traditional CAPM is contrasted against its augmented counterparts, with size and price-to-book value factors and size and liquidity factors respectively indicate that the latter has a greater impact on explanatory power. This finding transcends all of the Japanese regional market portfolios for top tier stocks as well as the aggregate market. These results add further support in a wider global markets context to the findings of the literature, such as Liu (2006) and Pastor and Stambaugh (2003), in applications that solely focussed on the US equity market. It also adds credibility to the continued use of the mean-variance paradigm in valuation.

The paper is structured as follows. Section 2 reviews the institutional features of Japanese regional equity markets while section 3 outlines data sources before introducing the liquidity measures and their construction and finally descriptive statistics. Section 4 outlines the two modelling approaches used: the size and liquidity augmented CAPM and its time varying parameter analogue. Section 5 discusses the empirical results. The final section concludes.

\section{JAPANESE REGIONAL MARKETS AND LIQUIDITY MEASUREMENT}

\section{(i). Japanese securities markets}


The current network of regional stock exchanges throughout Japan was formally established in 1949 following the end of the second World War, although many of the newly formed exchanges subsumed older existing regional exchanges that had been in place since the late nineteenth century. Currently there are five exchanges, Tokyo, Osaka, Nagoya, Fukuoka and Sapporo which have been shaped through a process of integration and consolidation. Exchanges such as Kyoto were merged into Osaka in 2001, Hiroshima and Niigata merged into Tokyo in 2000 and Kobe was dissolved in 1967 (TSE website, 2009). A new exchange to have been established in Japan is the Jasdaq, which initially served only as an OTC market, but since 2004 has had exchange and trading facilities formalised. The process of consolidation has continued during the millennium with the exploitation of economies of scale and scope through the joint establishment of the Japan Securities Clearing Corporation to facilitate clearing, settlement and payments amongst members of the national exchanges. Furthermore the 2003 establishment of a common Japanese central depository, the Japan Securities Clearing Corporation (JSCC), generating even greater economies of scope and scale through facilitating inter-market settlements and causing the disbandment of expensive individual clearing systems associated with each of the regional exchanges. Study of the regional exchanges and their effect on the local political economy is greatly facilitated by their all sharing the same legal regulatory regime, administered from Tokyo, stable common macroeconomic environment and homogeneous schedules of exchange commissions and fees.

\section{Tokyo}

The modern Tokyo stock exchange (TSE) traces it's origins to a much older Tokyo Stock Exchange Company Ltd that was established in 1878. This became the centre of the wartime Japan Securities Exchange (日本証券取引所 Nippon Shōken Torihikisho), itself established in 1943 through the merging of the then eleven regional Japanese stock exchanges. This was dissolved in 1947 with the current TSE being created in 1949 (TSE website, 2009). Open outcry trading was replaced by an electronic continuous auction system in 1999 and the exchange de-mutualised in 2001 changing its status from an incorporated association with its members as stakeholder (社団法人, shadan hōjin) to a joint stock corporation (TSE website, 2009). Trading is remote and from 9am to 11 am and 12$30 \mathrm{pm}$ to $15-00 \mathrm{pm}$ across the three market segments: the first and second tiers and the Tokyo Mothers Board ("Market of high-growth and emerging stocks") which is the development market (TSE website, 2009). Market barometer indices commonly used are the Nikkei 225 (Nikkei) which is the simple price-weighted average of top 225 Japanese stocks published by the Nihon Keizai Shimbun (Nikkei) business journal as well as the TOPIX 100 and 500 which are the capitalization weighted average of stocks taken from first tier of TSE. As would be expected from a large liquid market there is a relatively broad dispersion of capitalization and traded value across the TOPIX500 
stocks, although a significant proportion is concentrated in the top 100 stocks, as evident from Table 1.

\section{Table 1}

\section{Osaka}

The Osaka stock exchange (OSE) is the second largest stock exchange in Japan and differentiates itself from Tokyo in specialising in derivative instruments. The original Osaka financial market was established formally in 1878 although it traces its origins to the 1600's where it was the centre of rice commodities trading and transactions were undertaken in a form of rice futures contract (OSE website, 2009). Trading is electronic, in line with the TSE and operates similar hours. The market is also segmented into three listings compartments with the Hercules being the development market for SME firms (OSE website, 2009). The profile of the OSE (see Table 1) is similar to that of Tokyo with little concentration in capitalization and traded value, although as in the TSE most is accounted for by the top 100 stocks.

\section{Nagoya}

The Nagoya Stock Exchange (NSE) is the successor to the Nagoya Stock Exchange Co. Ltd., which was founded in 1886. It is the third largest exchange after Tokyo and Osaka and was de-mutualised in 2002. Since 2000 trading has been by electronic continuous auction via N-NET with the same hours as the TSE and OSE (NSE website, 2009). Equally alongside TSE and OSE the market has three listings segments with Centrex being the development market for SME firms. One of the most significant challenges facing the exchange is the achievement of genuine diversification of shareholdings and the effective dismantling of a strong network of cross-holdings that is a prominent feature of the political economy of Japanese regions (NSE website, 2009). The NSE has a noticeably more concentrated profile than either the TSE or OSE with the one stock alone accounting for $12.62 \%$ of capitalization and $15.60 \%$ of traded value.

\section{Fukuoka}

The Fukuoka stock exchange was established in 1949 and central to the financing needs of the regional Kyushu economy (FSE website, 2009) and currently has over 100 local firms listed, though many are only secondary listings. The exchange is de-mutualised, in line with the general trend in Japan, with electronic continuous auction trading operating similar hours to Tokyo, Osaka and Nagoya. A development board was instigated in 2000, "Q-Board", in order to make the exchange more accessible to the financing needs of the local business community, dominated by SME firms (FSE website, 2009). The profile of the FSE, as intuitively expected for a very small regional market is heavily concentrated with $15.76 \%$ of capitalization and $13.33 \%$ of traded value 
in one stock alone. The top 5 stocks account for just under half the market capitalization $(39.82 \%)$ and traded value (44.14\%) (see Table 1$)$.

\section{Sapporo}

The Sapporo stock exchange (SSE) was established in 1949 with 4 broker-member firms and 17 local listings. Despite the general governance trend in Japan towards the de-mutualisation of exchange the SSE has retained it's original de-mutualised management structure and forms a prominent part of the local financing needs of the distinctive Japanese region of Hokkaido with a current 77 listings, although only 22 are primary listed (SSE website, 2009). Trading is in line with other Japanese exchanges, with similar hours and operating an electronic continuous auction and in 2000 the SSE established it's own development board, the "Ambitious" market to better accommodate the financing needs of the local Hokkaido business community (SSE website, 2009). In line with the FSE the SSE has a heavily skewed profile with one stock alone accounting for $22.80 \%$ of capitalization and $26.13 \%$ of traded value. There is even greater concentration in the top 5 stocks with $57.38 \%$ capitalization and $67.71 \%$ of traded value (see Table 1 ).

\section{(ii). Liquidity constructs}

\section{The Bid Ask spread and commission cost}

The Bid Ask spread and commission cost: The data on the end of month bid and ask quotes were collected from Datastream. The bid-ask spread is calculated using the average of the available monthly quotes and incorporates at a minimum a single month's quote for that month. The average bid-ask spread spanning the quarter is used for the estimate of the spread. This procedure minimizes outlier problems and averages out the recording of either highs or lows in quotes resulting from monthly sampling. Following Lesmond (2005) bid-ask spreads that exceed $80 \%$ are trimmed as these are potentially errors. The monthly quoted spread is defined as:

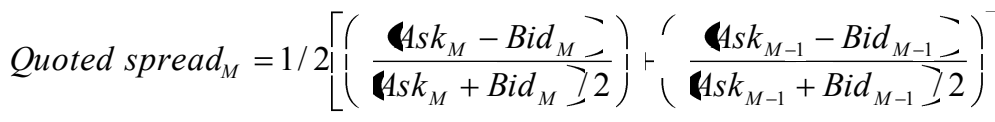

In order to estimate the total trading transaction costs, the costs associated with a round trade are added to the quoted spread for each month. Although there is a sliding scale of exchange fees contingent on traded value, there are no fees on trades less than $¥ 20$ billion (TSE website, 2009). Given the focus of this study is on the smaller regional exchanges where there is less participation of institutional investors and hence smaller size trades I have assumed brokerage and exchange fees to be zero.

\section{Turnover}

Daily trading volume data and shares outstanding data was obtained from Datastream. At first glance it is apparent that there is considerable variation in this measure on an intra-market basis. This reflects the substantial differences in both liquidity and turnover for many of the companies 
within each market. Any turnover statistics that exceed $100 \%$ of the shares outstanding in any month are trimmed from the sample. The shares-outstanding is determined at the start of the year and remains constant for the 12 months thereafter. The daily turnover measure is defined as:

$1 / D_{M} \sum_{t=1}^{M}$ volume $_{t} /$ shares - outstanding $_{-}$

where $D_{M}$ is the number of days in the month, $\mathrm{M}$.

\section{Amihud (2002) measure}

Daily price and volume data are sourced from Datastream. The daily security prices are scanned for data errors, omissions and delistings. Following the procedure outlined in Lesmond (2005) the prices are used calculate daily returns. To control for return outliers, a data error filter eliminates daily prices that are $+/-50 \%$ of the prior day's price and that day's price as well as previous day's price are deleted from sample. Equally if zero volume occurs on day $t$, then that day is deleted from average. Finally the measure is multiplied by $10^{6}$ as undertaken in Amihud (2002) in order to provide a common representation of measures and facilitate comparison. The Amihud measure is defined as:

$1 / D_{M} \sum_{t=1}^{M}\left|R_{t}\right|$ Price $_{t} \times$ Volume $_{t}^{-}$

\section{Liu (2006) measure}

Daily price and volume data are collected from Datastream. The measure is derived from the recent work of Liu (2006) and is defined as $\mathrm{LM}_{\mathrm{x}}$ which is the standardized turnover-adjusted number of zero daily trading volumes over the prior $\mathrm{x}$ months $(\mathrm{x}=1,6,12)$ i.e.

$L M_{x}=\left\ulcorner\right.$ Number of zero daily volumes in prior x months $\left.-+\frac{1 / \mathrm{x} \text { month turnover }}{\text { Deflator }}\right] * \frac{21 x}{\text { NoTD }}$

where $\mathrm{x}$ month turnover is the turnover over the prior $\mathrm{x}$ months, calculated as the sum of the daily turnover over the prior $x$ months, daily turnover is the ratio of the number of shares traded on a day to the number of shares outstanding at the end of the day, NoTD is the total number of trading days in the market over the prior $\mathrm{x}$ months, and Deflator is chosen such that,

$0<\frac{1 / \text { month turnover }}{\text { Deflator }}<$

for all sample stocks ${ }^{1}$. Given the turnover adjustment (the second term in brackets in first expression), two stocks with the same integer number of zero daily trading volumes can be distinguished: the one with the larger turnover is more liquid. As such the turnover adjustment acts as a tie-breaker when sorting stocks based on the number of zero daily trading volumes over the

\footnotetext{
${ }^{1}$ In line with Liu (2006) a deflator of 1,000 is used in constructing estimates for LM1
} 
prior $\mathrm{x}$ months. Because the number of trading days can vary from 15 to 23 , multiplication by the factor (21x/ NoTD) standardizes the number of trading days in a month to 21 which makes the liquidity measure comparable over time. LM1 can be interpreted as the turnover-adjusted number of zero daily trading volumes over the prior 21 trading days, which is the approximate average number of trading days in a month. The liquidity measure, $\mathrm{LM}_{\mathrm{x}}$ is calculated at the end of each month for each individual stock based on daily data. Daily data is available for all markets across entire sample period.

\section{(iii). Data: Sources}

Daily stock closing, bid and ask prices, total number of shares outstanding, traded volumes, dividend per share in local currency and converted into UK£ were obtained for all markets from Datastream. These data formed the basis of calculation of the daily return variance, or volatility, market capitalization, defined as total number of shares outstanding multiplied by daily closing price, and various liquidity constructs. The total returns series for each stock were sourced direct from Datastream for all markets. Exchange rate and UK- Gilt/Treasury yield data are sourced from Datastream. The one-month UK-Gilt/Treasury Bill yield rate represents the risk free rate although this is adjusted to take account of monthly excess returns as opposed to the quoted equivalent annualised rates. The conversion of the total returns series and prices into sterling and the use of UK - Gilt/Treasury yield rate assumes long term parity between Japanese Yen and sterling. Only stocks with a primary listing on the individual regional market were used. All estimation was undertaken in an international currency, UK£ sterling, to achieve greater international comparability with the literature.

\section{(iv). Data: Summary statistics relating to liquidity measures}

The evidence from Table 2 shows that as expected the profiles of the largest top tier stocks are considerably different from the overall aggregate market, although these differences gradually become less pronounced in the smaller regional markets of Nagoya, Fukuoka and Sapporo. The largest stocks exhibit lower bid-ask spreads, with for example 0.0038 in TOPIX 100 as compared to 0.07327 in TOPIX 500 constituents, and a similar movement in daily zero returns, with the top tier stocks having lower levels of inactivity and price-rigidity than the aggregate market, although this is less pronounced in the smaller regional markets to the extent of being reversed in Sapporo which is more a symptom of extremes of illiquidity across it's very low number of listings (22). There is also clear evidence of a size effect in all markets, with the mean cross sectional capitalizations of the large top tier bracket being several orders of magnitude larger than the overall market.

Table 2 
An assessment of the correlations between the key variables affecting the bid-ask spread and liquidity is provided in table 3. Given the variables have different measurement scales a nonprobability distribution limited correlation, the Spearman's rank, is used for the measurement of association. In addition to the bid-ask spread and the three liquidity measurement constructs, turnover, Liu and Amihud variables, price, daily price return volatility, traded volume, and market capitalization measures are introduced as control variables in line with those used in the investigations for price of trading immediacy undertaken by Stoll (2000). The rationale for the inclusion of these variables is based on order processing and inventory considerations of traders, albeit in a study undertaken by Stoll (2000) in the US equity market. Increases in volume and firm size increase the probability of locating a counterparty, thereby mitigating the risk of accepting and holding inventory risk. The stock price volatility, in local currency terms, provides an indication of the risk of adverse price changes of a stock placed on a trader's inventory, while the price measure itself controls for the effect of discreteness and is an additional proxy for risk in that low price stocks tend to be riskier. In this light the Liu metric is significantly, as indicated by correlations of over 50\%, negatively correlated with traded volume and turnover across all markets as would be expected given these variables play a significant role in it's construction. Similarly traded volume is positively correlated with the turnover metric, which is intuitive given the role of the former in the construction of he latter, for all markets bar Nagoya where it is only marginally insignificant. Uniquely traded volume has a large positive correlation with capitalization, or firm size, for only the two smallest and most illiquid markets, namely Fukuoka and Sapporo. This would indicate that investor confidence resides in larger well known stocks in the presence of a lack of diversification opportunities and extremes of illiquidity. Market capitalization, or firm size, is also positively correlated to the Amihud metric for the all markets except the smallest, most illiquid, Sapporo. The correlations in the Sapporo market are unique, largely owing to its very small size and illiquidity. Correlations between liquidity constructs and other control variables, while in line with those of the other regional markets, are significantly stronger. A prominent example are the correlations between Liu and every other variable and metric except for the Amihud measure which is more an indication that when the little activity there is occurs then it is likely to affect all variables equally rather than being a true measure of illiquidity.

\section{Table 3}

\section{EMPIRICAL MODELS}

This section considers two conditional modelling strategies, namely the three-factor linear CAPM and its time varying parameter counterpart.

\section{(i). Size and Liquidity Augmented CAPM}


The standard Fama and French (1993) model augments the traditional CAPM with size (SMB) and price to book value (PBV) returns-based factors that proxy the hypothesized underlying state variables. Therefore, the expected excess returns on a portfolio $\mathrm{p}$ of emerging market stocks can be written as

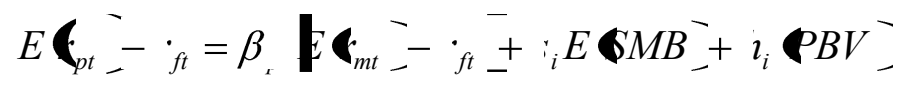

The equilibrium relation of the three factor model is stated in terms of expected returns. In order to test the model with historical data, it is necessary to transform (6) to the following estimating equation:

$$
r_{i t}-{ }_{f t}=x+\beta\left(r_{m t}-{ }_{f t}\right)+{ }_{i} S M B_{t}+i_{i} P B V_{t}+\vdots
$$

where the variables are described above and $\varepsilon$ is an independently identically distributed (iid) disturbance term. Furthermore and following in the spirit of the above Fama and French model I augment the one-factor CAPM with size (SMB) and liquidity (ILLIQ) factors in order to create a size-liquidity three factor model in line with Shum and Tang (2005) and Martinez et al (2005). Therefore, the expected excess returns on a portfolio $\mathrm{p}$ of emerging market stocks can be written as

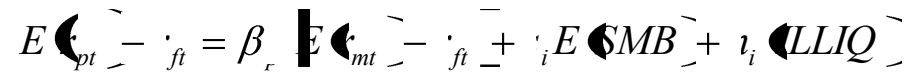

In line with the above this can be transformed in order to test historical data into the following equation:

$$
r_{i t}-{ }_{f t}=x+3\left(r_{m t}-{ }_{f t}\right)+{ }_{i} S M B_{t}+i_{i} I L L I Q_{t}+:
$$

where the variables are described above and $\varepsilon$ is an independently identically distributed (iid) disturbance term. The model is estimated on a time series basis using standard Ordinary Least Squares (OLS) techniques, as opposed to the Fama and Macbeth (1973) rolling cross section approach, with the expectation that the Jensen alpha, or regression intercept, should not be statistically different from zero given the theoretical relationship between an individual portfolios expected returns and those of the market (Markowitz, 1959). However Scholes and Williams (1977) provide evidence against the employment of standard OLS techniques with findings that beta estimations are biased downwards for securities infrequently trading and upwards for those traded more often. Dimson (1979) builds on this evidence in the inefficiency of beta estimation in thinly traded stocks and proposes a correction technique based on the aggregation of betas from lagged and leading regression coefficients. Dimson and Marsh (1983) propose a second correction technique which uses a trade-to-trade method measuring and matching returns between individual stocks or portfolios and the market index between the times of the last trades in successive months. I justify the use of standard OLS techniques here in order to closely follow the literature of Pastor and Stambaugh (2003), Liu (2006) and Martinez (2005) who use these techniques extensively in their studies involving multifactor CAPM models capturing liquidity effects. However the 
limitations of standard OLS techniques must be taken into account particularly when they are applied to the very small and illiquid markets such as Fukuoka and especially Sapporo.

\section{(ii). Time varying parameter CAPM model}

Following Brooks et al (1998) the time varying parameter analogue of the linear CAPM employs the Kalman filter and relies on the notion of "state space" in estimating the conditional constant term and market beta of the multifactor analogue of CAPM. This is represented by an observation, or measurement/signal, equation and a transition, or state, equation, that in combination express the structure and dynamics of a time varying system. A state space model is specified where an observation at time $t$ is a linear combination of a set of variables, known as state variables, which compose the state vector at time $\mathrm{t}$. Assuming the number of state variables is $\mathrm{m}$ and the $(\mathrm{m} \times 1)$ vector is $\theta_{\mathrm{t}}$ then the observation equation can be represented by:

$$
y_{t}=z_{t} \theta_{t}+t_{t}, \quad \mu_{t} \sim N\left(0, \sigma_{r,}\right)
$$

where $z_{t}$ is assumed to be known ( $\left.\mathrm{m} \times 1\right)$ vector, and $\mu$ is the observation error. The disturbance $\mu$ is assumed to be normally distributed with zero mean. The set of state variables is defined from the minimum set of information from past and present data and future values of time series are completely determined by the present values of the state variables, known as the Markov property. The state space model incorporates unobserved variables within, and estimates them alongside the observable model, in imposing a time varying structure of the CAPM beta. The conditional betas are estimated using the following observation, or signal equation:

$R_{i t}=\alpha+\beta{ }^{\text {alman }} R_{M t}+s_{i}{ }^{\text {Kalman }} S M B+h_{i}{ }^{\text {Kalman }} I L L I Q+\varepsilon, \quad \varepsilon \sim N(0, \Omega$

where $\mathrm{R}_{\mathrm{it}}$ and $\mathrm{R}_{\mathrm{Mt}}$ are the excess returns of individual portfolio and market portfolios at time $\mathrm{t}$ and $\varepsilon$ is disturbance term. The exact form of the related transition equation depends on the form of stochastic process the betas are assumed to follow and in this case a simple random walk process is imposed as outlined in Brooks et al (2000). The transition equation is defined:

$$
\begin{aligned}
& \alpha^{\text {alman }}=\chi_{-}^{\text {alman }}+7 \ldots \quad \eta_{\ldots} \sim N(0, Q) \\
& \beta^{\text {alman }}=\beta_{-}^{\text {alman }}+1, \quad \eta_{r} \sim N(0, Q) \\
& s_{i t}^{\text {Kalman }}={ }_{i t-}^{\text {Kalman }}+1, \quad \eta \sim N(0, Q) \\
& h_{i t}^{\text {Kalman }}=i_{i t-}^{\text {Kalman }}+1, \quad \eta \sim N(0, Q)
\end{aligned}
$$

Together equations 11 and the combination of 12 to 15 constitute a Kalman filter state space model. However a set of prior conditional values are necessary for the Kalman filter to forecast the future value and is expressed as:

$$
\alpha^{\text {alman }} \sim N\left(\alpha^{\text {alman }}, P_{0}\right)
$$




$$
\begin{aligned}
& \beta^{\text {alman }} \sim N\left(\beta^{\text {alman }}, P_{0}\right) \\
& s_{0}^{\text {Kalman }} \sim N\left(s_{0}^{\text {Kalman }}, P_{0}\right) \\
& h_{0}^{\text {Kalman }} \sim N\left(h_{0}^{\text {Kalman }}, P_{0}\right)
\end{aligned}
$$

Brooks et al (1998) cite that this technique uses the first two observations to establish the prior conditions and then recursively estimates the entire series providing conditional estimates of $\beta^{\text {alman }}, s_{i t}^{\text {Kalman }}, h_{i t}^{\text {Kalman }}$ and $\alpha^{\text {alman }}$.

\section{RESULTS}

(i) An assessment of liquidity measures ability in explaining total costs

The regression results are reported in Table 4 for the five Japanese regional markets which are at an overall level with the TOPIX 500 being used for Tokyo. In all cases, except Tokyo, the sign of the market control variables is of the expected direction i.e. negative for price and volume and positive for size and volatility which is in line with theory (Stoll, 2000; Lesmond, 2005). Tokyo is exceptional where volatility is negative although alongside volume it is not statistically significant. Similarly in the smaller illiquid regional markets of Nagoya and Sapporo size is negative while also being not statistically different from zero which is a noticeable departure from theory. The explanatory power of the regression models is good with $\mathrm{R}^{2}$ of over $90 \%$ evident for Tokyo and progressively decreasing to $62 \%$ for Nagoya and then lower still at over $37 \%$ for Osaka, $34 \%$ for Sapporo and 30\% for Fukuoka.

The results for the sequential addition of additional liquidity measures alongside the Stoll control variables indicate that either the turnover or Liu metrics have the greatest impact for Tokyo, although this is largely indiscernible on the basis of increased explanatory power and can only be differentiated by statistical significance of this variable once included. The inclusion of the Amihud and Liu constructs in regression models for Osaka also only result in slightly increased explanatory power while the variables themselves are highly statistically significant. The results for Nagoya and Fukuoka are ambiguous given no additional liquidity construct results in increased explanatory power and none are statistically significant. However the addition of the Amihud construct to regressions for Sapporo results in considerable increases in explanatory power and also the statistical significance of this variable. These results would indicate at this stage that the Amihud variable is most suitable variable to measure liquidity although given the levels of ambiguity present they are far from conclusive.

Table 4

(ii). Contrasting the liquidity measures: Vuong likelihood ratio test 
The maximum likelihood method of Vuong (1989) (see Appendix 1 for description of empirical methods employed) offers a robust alternative to regression-based methods that merely test the level of association between the Stoll market control variables and the various liquidity constructs against the total trading costs with relative strength being assessed on the basis of statistical significance and explanatory power. The tests proposed in Vuong (1989) use a one-sided Zprobability distribution to assess the confidence levels arising from the study of which liquidity measures better explain the data generating process behind the total trading costs.

The evidence from Table 5 indicates that the Stoll market control variables are better at explaining the underlying total trading costs data generating process than either the Liu or Amihud liquidity constructs. However the turnover measure does not offer a viable alternative as both Liu and Amihud measures are significantly better at explaining total trading costs. There is very little evidence to clearly distinguish the performance of Liu over and above that of Amihud and thus make a unambiguous decision regarding the robustness of one particular metric above all others. In this light I choose the Liu measure for modelling liquidity in next sections owing to its ability to transcend the multidimensional properties of liquidity, where both the alternative measures are only able to capture single-dimensional effects of the liquidity phenomenon.

Table 5

\section{(iii). Summary statistics relating to size-liquidity sorted portfolios}

Table 6 presents the descriptive statistics for the nine size - liquidity sorts portfolios and separately the nine size - price-to-book value sorted portfolios, with the latter representing the process involved in obtaining the factors for the Fama and French (1993) valuation model. Generally the mean returns in panels A and B are positive while skewness and kurtosis are minimal indicating that the distribution of returns conforms to a standard Normal distribution which is further reinforced by the very low Jarque-Bera statistics. However there are some discernable differences across the portfolios. Evidence from panel A shows that returns are consistently lower for high illiquidity portfolios than for those of low illiquidity which is matched in reverse by higher standard deviations, or volatility, for the former and lower standard deviation for the latter. This is reversed for the size-to-price to book value sorted portfolios in panel B. Returns are lower for high price-tobook value portfolios than for those with a low ratio and correspondingly standard deviations are lower for high price-to-book value than for low. The dispersion of stocks across portfolios that occurred during the size-liquidity/ price-to-book value sorting process is evident from panel C. Tokyo stocks are overwhelmingly concentrated in the big size portfolios, spanning across liquidity categories, while those spilling over into the medium size portfolios are largely concentrated in the high illiquidity portfolio (53.82) with far fewer in the low liquidity portfolio (40.81). Osaka stocks are overwhelmingly concentrated in the three small size portfolios with those falling in the medium size portfolio being evenly distributed across liquidity categories, unlike previously in Tokyo. 
Similarly Nagoya stocks fall in the three small size portfolios and then a lesser number in the medium size portfolios though with the majority falling in the low illiquidity categories. The very small markets of Fukuoka and Sapporo are quite different. Numbers are much smaller and while they are concentrated in the small and then medium size portfolios in both in Fukuoka these are concentrated in the medium illiquidity category, while in Sapporo they are polarised between high and low illiquidity with none falling in medium illiquidity.

\section{Table 6}

The evidence from panel D shows that there is little correlation between the returns-based factors, MARKET, SMB, ILLIQ and PBV. This is in line with theory (Pastor and Stanbaugh, 2003) where zero cost portfolios proxying underlying state variables should have little or no correlation which also mitigates concerns over potential multicollinearity from their inclusion ion regression-based models such as the time series augmented CAPM. However the negative values of mean returns of the SMB, PBV and ILLIQ factors imply the likely presence of reverse size effects from that in Fama and French (1993) where returns steadily decrease as stock size increases.

The descriptive statistics of the portfolios constituting the largest top tier brackets of stocks as well as overall aggregate markets also reveal substantial differences between markets. Mean returns are exclusively negative for all the smaller regional Japanese markets, i.e. Nagoya overall, Fukuoka and Sapporo. However differences in standard deviations are negligible and both skewness and kurtosis statistics indicate that returns distributions conform to a standard Normal distribution. The presence of negative excess returns would question the viability of the smaller exchanges in terms of being able to attract long term institutional investors which would suggest that there is an alternative motivation behind Japan's distinctive regional stock exchanges such as to serve the interests of the local political economy.

\section{(iv). Performance of traditional CAPM against three-factor CAPM}

Table 7 documents the results from the time series regressions of the traditional CAPM and the two sets of three factor augmented CAPM, namely the size - liquidity CAPM and size - price-to-book value CAPM. The evidence would suggest that while there is an increase in explanatory power between the traditional CAPM and it's three factor counterpart there is actually little discernable benefit between the addition of the liquidity or the price-to-book value factors. The Jensen alpha, $\alpha_{p}$, terms in both the traditional CAPM as well as its three factor counterpart are not statistically different from zero, indicating a good fit with theory (Markowitz, 1959) and also providing evidence of asset market integration and a lack of segmentation across the equity markets in Japan which would be expected from a homogeneous macroeconomic, legal and regulatory environment and payments system. In all cases, bar the small size - medium illiquidity portfolio, the size, liquidity and price-to-book value factors are statistically significant although there is considerable 
dispersion in the absolute size of the coefficients (betas). Those of the big and small size portfolios are large, demonstrating the importance of size premiums in explaining returns, while those on the big size portfolios within the size - price-to-book value portfolios are negative indicating the presence of a reverse size effect where returns for the largest stocks actually decrease as firm size increases. This behaviour is not expected and is indicative of a reversal of the documented "size effect" that effects the valuation of smaller firms (Martinez et al, 2005). This is the opposite of what would be expected and does not provide investors with good hedging opportunities. The betas on the high illiquidity/ price-to-book value portfolios across each of the three size categories are positive indicating the presence of a reverse illiquidity effect, where returns actually increase as illiquidity increases and as price-to-book value increases. Thus, as with the results for the smallsize portfolios, a different valuation method would be needed to price very high illiquidity stocks and firms accurately. The estimated coefficients on the illiquidity factor-mimicking portfolios are negative for low and medium-illiquidity portfolios indicating as expected that more liquid firms experience a decrease in expected returns when aggregate market illiquidity increases. In general, the coefficients on the low-illiquidity and medium-illiquidity portfolios are negative, as one would expect, with firms paying lower returns when the illiquidity variable increases. However, the coefficients on the high-illiquidity portfolios are positive indicating that these companies pay higher returns when the illiquidity measure increases. The increased explanatory power of these models illustrates that the size-liquidity augmented CAPM is appropriate for a range of markets although it offers only a marginal improvement over and above the Fama and French (1993) size - price-tobook value counterpart. As a result and in order to achieve brevity at this stage I omit further study of the Fama and French model and focus my study retaining the size - liquidity factors.

Table 7

\section{(v) Modelling market portfolios}

Country and industry portfolios were formed from the simple price-weighted averages of stock returns across stocks aggregated into either industries or countries. The time invariant CAPM, sizeilliquidity and size-price-to-book value augmented CAPM models were applied to the portfolios with results reported in Table 8.

\section{Average Returns in Tokyo}

The results for the top tier TOPIX100 and overall TOPIX500 index constituents indicate a good fir with theory given all Jensen alpha terms are not statistically significant, size betas are positive, large and statistically significant and liquidity betas are negative while statistically significant. However while both size and liquidity factors are significant and lead to increased explanatory power in TOPIX100 portfolio the addition of the size term in the TOPIX500 portfolio causes the Jensen alpha to become statistically significant despite the increase in $\mathrm{R}^{2}$, indicating a lack of fit 
with prevailing theory and that these stocks are segmented from the market universe. A two factor model, including only the liquidity factor, is preferable in explaining returns for TOPIX500 firms, where explanatory power is increased but the Jensen alpha remains insignificant.

\section{Table 8}

\section{Average Returns in Osaka}

The results for the Osaka Top 50 stocks portfolio indicate that the Jensen alpha is statistically significant for all models inferring low levels of integration with the Japanese market universe. However the size betas are negative and significant inferring the presence of a reverse size effect where returns decrease as firm size increases. The liquidity betas are negative but also not significant and their addition does not cause any increase in explanatory power inferring that the top stocks alone can be modelled using a two factor model including size premiums. In contrast the results for the overall Osaka market indicate that Jensen alphas are not significant for any of the models while the addition of both the size and liquidity betas cause increases in explanatory power and are relevant in explaining returns.

\section{Average Returns in Nagoya}

The inclusion of either the size or liquidity factor alone causes the explanatory power of the model to increase for the portfolio of the top 20 stocks in Nagoya, although the latter has the greatest increase resulting in an $\mathrm{R}^{2}$ of $82.66 \%$. Contrastingly the addition of both size and liquidity factors leads to the highest explanatory power, with an $\mathrm{R}^{2}$ of $92.30 \%$, for the overall Nagoya market. In both the top tier stocks and overall market size betas are negative, indicating a decrease in returns as firm size increases, and liquidity betas are both large and positive indicating a large liquidity effect where returns increase alongside illiquidity. This is evidence of the limitations of the CAPM methodology when applied to smaller and more illiquid markets such as Nagoya.

\section{Average Returns in Fukuoka and Sapporo}

The evidence would suggest that returns in Fukuoka, one of the two smallest regional markets, are largely driven by a large, positive and significant liquidity premium, given that in both the top 10 portfolio and in the overall market the addition of the liquidity factor alone leads to the highest $\mathrm{R}^{2}$ (49.79\% for top 10 and $68.59 \%$ for overall). The Jensen alpha term of all models is not statistically significant indicating a lack of segmentation with the Japanese market universe which is in line with theory.

\section{Average Returns in Sapporo}

The results for Sapporo are similar to Fukuoka and Nagoya. Both size and liquidity betas are significant and lead to an increase in explanatory power. However while the addition of the 
liquidity factor alone in the top 5 stocks portfolio leads to an $\mathrm{R}^{2}$ of $35.41 \%$ the combination of size and liquidity factors in the overall market causes an $\mathrm{R}^{2}$ of $57.52 \%$. In line to both Fukuoka and Nagoya liquidity betas are large and positive and size betas are negative questioning the validity of the CAPM in such small markets.

\section{(iv) Modelling industry portfolios with time varying techniques}

The time varying coefficient model based on the augmented CAPM was only estimated including market, size and illiquidity factors. There is contrast between the evidence in Table 9 and from the previous section with a notable failure to achieve maximum likelihood convergence for the overall Nagoya market. Equally the time series means of liquidity betas are generally negative, as would be expected inferring that increases in aggregate illiquidity lead to decreases in returns. However with the exception of Tokyo's TOPIX100 and Sapporo's Top 5 size betas are negative and in line with the evidence from previous section. These results would provide some support that illiquidity factor does have an important role in valuation using this time varying methodology.

Table 9

Figures 1 to 3 provide time series plots of the evolution of the liquidity betas across the overall market portfolios for those markets where maximum likelihood convergence was achieved using the Kalman filter methodology. The evidence from these figures reveals that there has been a considerable increase in the size and significance (shown by the lower standard error band becoming positive) for liquidity betas in the overall markets of Sapporo and Fukuoka since the onset of the global financial crisis of 2007/2008. Tokyo's TOPIX500 in contrast is relatively unaffected with no discernable change in it's long term trend. This would infer that as investor confidence in assets perceived to be more risky and illiquid decreased worldwide liquidity was lost from smaller exchanges to larger deeper markets.

\section{Figures 1 - 3}

\section{(iv) Costs of equity estimation}

The evidence from Table 10 reveals that costs of equity are lowest in the top bracket of stocks across all markets, as would be expected. However the time invariant regression methods indicate that the smallest markets of Sapporo and Fukuoka have the highest costs of equity while the larger more liquid markets of Tokyo and Osaka have the lowest. While this progression in costs of equity is generally followed for the time varying method in the top stocks bracket, it is somewhat reversed in the overall markets with Fukuoka, Tokyo TOPIX500 and Sapporo having the lowest values $(7.21 \%, 7.53 \%$ and $8.00 \%$ respectively) and Osaka the highest (10.23\%).

\section{Table 10}




\section{CONCLUSIONS}

This study proposes a size and liquidity augmented capital asset pricing model to explain the cross section of expected returns in Japanese regional stock markets, an area which has previously been excluded from empirical research in finance. The major international exchanges of Tokyo and Osaka are used alongside the much smaller Nagoya, Fukuoka and Sapporo markets that play a very prominent role in the financing needs of Japan's powerful localised political economy.

The performance of the size and liquidity augmented three factor CAPM is contrasted with the size and price-to-book value three factor model proposed in Fama and French (1993) and is found to offer only marginal improvements in explanatory power across the cross section of stock returns. However the application of time varying techniques, employing the market, size and liquidity factors used in the time invariant CAPM regressions do reveal that the smaller regional markets of Fukuoka and Sapporo have experienced a considerable increase in absolute size and significance of their exposures to aggregate Japanese illiquidity which is not apparent in the larger Tokyo market since the onset of the 2007/2008 global financial crisis. Equally returns in the smaller markets of Nagoya, Fukuoka and Sapporo are driven by a considerable liquidity premium which is reflected in higher costs of equity inferring that these exchanges are not as competitive as the larger Tokyo and Osaka exchanges for sourcing cost effective finance. This in turn would explain the high level of secondary listings on the smaller markets and their comparative inability to attract new primary listings. 


\section{REFERENCES}

Amihud, Y., 2002. Illiquidity and stock returns: cross section and time series effects. Journal of Financial Markets 5, 31-56

Amihud, Y., Mendelson, H., 1986. Asset pricing and the bid-ask spread. Journal of Financial Economics 17, 223-249

Bekaert, G., Harvey, C., 1995. Time-varying world market integration. Journal of Finance 50, 403444

Bremer, M., Hiraki, T., 1999. Volume and individual security returns on the Tokyo Stock Exchange. Pacific-Basin Finance Journal 7, 351-370

Brooks, R. D., Faff, R.W., McKenzie, M. D., 1998. Time-varying beta risk of Australian industry portfolios: A comparison of modelling techniques. Australian Journal of Management 23(1), 1-22

Choe, C. (2007) The poitical economy of SME financing and Japan's regional bank problems. Pacific-Basin Finance Journal, 15, 353-367

Chan, L.K.C., Hamao, Y., Lakonishok, J., 1991. Fundamentals and stock returns in Japan. Journal of Finance 46, 1739-1764

Chang, Y. Y., Faff, R., Hwang, C-Y., 2010. Liquidity and stock returns in Japan; New evidence. Pacific-Basin Finance Journal 18, 90-115

Daniel, K., Titman, S., Wei, K.C.J., 2001. Explaining the cross-section of stock returns in Japan: factors or characteristics? Journal of Finance 56, 743-766

Datar, V.T., Naik, N.Y., Radcliffe, R., 1998. Liquidity and stock returns: An alternative test. Journal of Financial Markets 1, 203-219

Dimson, E., 1979. Risk measurement when shares are subject to infrequent trading. Journal of Financial Economics 7, 197-226

Dimson, E., Marsh, P., 1983. The stability of UK risk measures and the problem of thin trading. Journal of Finance 38, 753-783

Fama, E., French, K., 1993. Common risk factors in the returns on stocks and bonds. Journal of Financial Economics 33, 3-56

Fama, E.F., Macbeth, J.D., 1973. Risk, return and equilibrium: empirical tests. Journal of Political Economy 81, 607-636

FSE website, 2009. Fukuoka Stock Exchange. http://www.fse.or.jp/ Accessed 22 December 2009 Grout, P.A., Zalewska, A., 2006. The impact of regulation on market risk. Journal of Financial Economics 80, 149-184

Hamao, Y., Hasbrouck, J., 1995. Securities trading in the absence of dealers: trades and quotes on the Tokyo Stock Exchange. Review of Financial Studies 8, 849-878

Lee, C., 1993. Market fragmentation and price-execution in NYSE-listed securities. Journal of Finance 48, 1009-1038 
Lehmann, B.N., Modest, D.M., 1994. Trading and liquidty on the Tokyo Stock Exchange: a bird's eye view. Journal of Finance 49, 951-984

Lesmond, D.A., 2005. Liquidity of emerging markets. Journal of Financial Economics 77, 411-452

Liu, W., 2006. A Liquidity-augmented capital asset pricing model. Journal of Financial Economics $82,631-671$

Markowitz, H., 1959. Portfolio Selection: Efficient Diversification of Investments. New York: John Wiley and Sons; London: Chapman and Hall.

Martinez, M.A., Nieto, B., Rubio, G., Tapia, M., 2005. Asset pricing and systematic liquidity risk: An empirical investigation of the Spanish stock market. International Review of Economics and Finance 14, 81-103

NSE website, 2009. Nagoya Stock Exchange. http://www.nse.or.jp/e/ Accessed 22 December 2009

O'Hara, M., 2003. Presidential address: liquidity and price discovery. Journal of Finance 58, 13351354

OSE website, 2009. Osaka Securities Exchange. http://www.ose.or.jp/e/stocks/index.html Accessed 22 December 2009

Pastor, L., Stambaugh, R., 2003. Liquidity risk and expected stock returns. Journal of Political Economy 111, 642-685

Pettengill, G., Sundaram, S., Mathur, I., 1995. The conditional relation between beta and returns. Journal of Financial and Quantitative Analysis 30, 101-116

Scholes, M., Williams, J.T., 1977. Estimating betas from nonsynchronous data. Journal of Financial Economics 5, 309-327

Shum, W.C., Tang, G.Y.N., 2005. Common risk factors in returns in Asian emerging stock markets. International Business Review 14, 695-717

SSE website, 2009. Sapporo Securities Exchange. http://www.sse.or.jp/ Accessed 22 December 2009

Stoll, H.R., 2000. Friction, Journal of Finance 55, 1480-1514.

TSE website, 2009. Tokyo Stock Exchange. http://www.tse.or.jp/english/ Accessed 22 December 2009

Vuong, Q., 1989. Likelihood ratio tests for model selection and non-nested hypotheses, Econometrica, 307-333 
Table 1 Market Capitalisation and Turnover profiles, 2008

\begin{tabular}{|c|c|c|c|c|c|}
\hline & Tokyo (TOPIX 500) & Osaka & Nagoya & Fukuoka & Sapporo \\
\hline \multicolumn{6}{|c|}{ Proportion market capitalisation to total (\%) } \\
\hline Top 1 & 6.63 & 4.42 & 12.62 & 15.76 & 22.80 \\
\hline Top 10 & 22.50 & 25.37 & 38.67 & 63.66 & 86.08 \\
\hline Top 20 & 32.73 & 36.97 & 55.84 & 88.24 & 97.15 \\
\hline Top 50 & 51.23 & 56.67 & 81.89 & -- -- & -- -- \\
\hline \multicolumn{6}{|c|}{ Proportion Turnover value to total (\%) } \\
\hline Top 1 & 9.98 & 20.64 & 15.60 & 13.33 & 26.13 \\
\hline Top 5 & 20.18 & 50.56 & 46.63 & 44.14 & 67.71 \\
\hline Top 10 & 27.43 & 67.74 & 61.29 & 73.36 & 91.37 \\
\hline Top 20 & 37.25 & 81.29 & 74.29 & 93.81 & 99.98 \\
\hline Top 50 & 56.00 & 93.02 & 93.08 & -- -- & -- -- \\
\hline Top 100 & 73.91 & 97.11 & 99.99 & -- -- & -- -- \\
\hline
\end{tabular}

Source: Compiled by authors from Bloomberg and Datastream

Notes: * indicates number of primary listed stocks 
Table 2 Summary Statistics

\begin{tabular}{|c|c|c|c|c|c|c|c|c|}
\hline \multirow[b]{2}{*}{ Country } & \multirow[b]{2}{*}{$\begin{array}{l}\text { No. Firms by } \\
\text { trading activity }\end{array}$} & \multirow{2}{*}{\multicolumn{2}{|c|}{$\begin{array}{c}\text { Local market } \\
\text { Price }\end{array}$}} & \multirow[b]{2}{*}{$\begin{array}{c}\text { Volume } \\
\text { (thousands) }\end{array}$} & \multicolumn{3}{|c|}{ £UK equivalent } & \multirow[b]{2}{*}{$\begin{array}{c}\text { Bid-Ask spread } \\
(\%)\end{array}$} \\
\hline & & & & & $\begin{array}{c}\text { Market } \\
\text { Capitalization } \\
\text { (millions) }\end{array}$ & Price & $\begin{array}{c}\text { Market } \\
\text { Capitalization } \\
\text { (millions) }\end{array}$ & \\
\hline \multirow{4}{*}{ Tokyo } & 100 & 10.24 & $34,747.09$ & $135,454.68$ & $1,977,955.01$ & 168.08 & $9,865.18$ & 0.0038 \\
\hline & (TOPIX 100) & [9.18] & {$[31,934.68]$} & {$[130,069.65]$} & {$[1,856,541.90]$} & {$[164.27]$} & {$[10,182.75]$} & {$[0.0035]$} \\
\hline & 500 & 15.57 & $18,827.84$ & $85,915.39$ & $1,035,508.19$ & 95.25 & $4,787.94$ & 0.07327 \\
\hline & (TOPIX 500) & {$[13.49]$} & {$[11,129.47]$} & {$[58,131.20]$} & {$[666,809.00]$} & {$[62.50]$} & {$[3,410.32]$} & {$[0.04842]$} \\
\hline \multirow{4}{*}{ Osaka } & & 30.89 & $29,322.14$ & 866.45 & $32,415.94$ & 142.66 & 161.76 & 0.01666 \\
\hline & 50 & {$[29.66]$} & {$[16,112.08]$} & [818.93] & {$[28,643.61]$} & {$[104.25]$} & {$[159.71]$} & {$[0.01630]$} \\
\hline & & 34.96 & $30,822.14$ & $1,320.09$ & $10,263.71$ & 152.47 & 51.38 & 0.02687 \\
\hline & Uverall & [34.19] & {$[24,821.69]$} & {$[965.13]$} & {$[9,312.59]$} & [128.64] & {$[45.96]$} & {$[0.02488]$} \\
\hline \multirow{4}{*}{ Nagoya } & & 50.45 & 946.07 & 224.30 & $28,130.80$ & 4.77 & 141.86 & 0.01360 \\
\hline & $10 p 20$ & [49.87] & [937.75] & [195.60] & {$[26,616.86]$} & [4.92] & [148.43] & {$[0.01313]$} \\
\hline & & 62.16 & $13,170.77$ & 159.52 & $11,653.13$ & 64.50 & 59.58 & 0.02040 \\
\hline & Overall & [61.87] & {$[11,004.90]$} & [135.79] & {$[9,442.23]$} & {$[68.60]$} & [46.37] & [0.02002] \\
\hline \multirow{4}{*}{ Fukuoka } & & 67.77 & $1,601.68$ & 140.93 & $24,735.30$ & 7.82 & 126.85 & 0.02159 \\
\hline & $10 p 10$ & [69.34] & [880.08] & {$[125.52]$} & {$[26,016.28]$} & {$[4.67]$} & {$[132.20]$} & [0.01966] \\
\hline & & 73.53 & $9,176.30$ & 60.17 & $10,695.56$ & 45.01 & 54.83 & 0.03384 \\
\hline & Uverall & [73.06] & {$[8,592.36]$} & [57.17] & {$[11,446.94]$} & [59.93] & {$[58.31]$} & {$[0.03608]$} \\
\hline \multirow{4}{*}{ Sapporo } & Ton 5 & 81.17 & $10,689.21$ & 24.73 & $11,117.21$ & --- & 56.62 & 0.03502 \\
\hline & $10 p 5$ & {$[83.45]$} & [482.82] & [22.85] & {$[10,717.95]$} & --- & {$[55.60]$} & {$[0.02656]$} \\
\hline & & 77.92 & $14,839.77$ & 43.35 & $4,558.53$ & & 23.14 & 0.05151 \\
\hline & Overall & [78.13] & {$[10,683.07]$} & [28.95] & {$[4,523.01]$} & & {$[23.38]$} & {$[0.03905]$} \\
\hline
\end{tabular}


Table 3 Spearman's Rank Correlations

\begin{tabular}{|c|c|c|c|c|c|c|c|c|}
\hline \multicolumn{9}{|c|}{ Panel A: Results for Tokyo (TOPIX 500) (2001M04 - 2009M06) } \\
\hline & Liu & Price & Volatility & Volume & MV & Amihud & Turnover & Bid Ask Spread \\
\hline Liu & 1.0000 & & & & & & & \\
\hline Price & 0.0239 & 1.0000 & & & & & & \\
\hline Volatility & -0.3826 & -0.0287 & 1.0000 & & & & & \\
\hline Volume & -0.5515 & -0.4580 & 0.1567 & 1.0000 & & & & \\
\hline MV & 0.0100 & 0.2889 & -0.0649 & 0.4215 & 1.0000 & & & \\
\hline Amihud & 0.4956 & -0.2338 & 0.0729 & -0.6655 & -0.7461 & 1.0000 & & \\
\hline Turnover & -0.9950 & -0.0232 & 0.3855 & 0.5519 & -0.0133 & -0.4966 & 1.0000 & \\
\hline Bid Ask Spread & 0.1963 & -0.0836 & 0.1355 & -0.2417 & -0.2505 & 0.3693 & -0.1942 & 1.0000 \\
\hline \multicolumn{9}{|c|}{ Panel B: Results for Osaka (2001M04 - 2009M06) } \\
\hline Liu & 1.0000 & & & & & & & \\
\hline Price & 0.1586 & 1.0000 & & & & & & \\
\hline Volatility & -0.3087 & -0.1391 & 1.0000 & & & & & \\
\hline Volume & -0.7781 & -0.4670 & 0.2160 & 1.0000 & & & & \\
\hline MV & -0.2011 & 0.4088 & -0.2236 & 0.2199 & 1.0000 & & & \\
\hline Amihud & 0.5621 & -0.3791 & 0.0899 & -0.4182 & -0.5331 & 1.0000 & & \\
\hline Turnover & -0.6196 & -0.0596 & 0.4537 & 0.5125 & -0.2431 & -0.4561 & 1.0000 & \\
\hline Bid Ask Spread & 0.3611 & -0.3737 & 0.1628 & -0.1553 & -0.4008 & 0.6244 & -0.2206 & 1.0000 \\
\hline \multicolumn{9}{|c|}{ Panel C: Results for Nagoya (2001M04 - 2009M06) } \\
\hline Liu & 1.0000 & & & & & & & \\
\hline Price & 0.0861 & 1.0000 & & & & & & \\
\hline Volatility & -0.1714 & -0.1234 & 1.0000 & & & & & \\
\hline Volume & -0.7834 & -0.3728 & 0.1162 & 1.0000 & & & & \\
\hline MV & -0.3504 & 0.4215 & -0.2162 & 0.3570 & 1.0000 & & & \\
\hline Amihud & 0.3064 & -0.5478 & 0.3834 & -0.2075 & -0.5317 & 1.0000 & & \\
\hline Turnover & -0.5967 & 0.0091 & 0.3595 & 0.4831 & -0.1918 & -0.2849 & 1.0000 & \\
\hline Bid Ask Spread & 0.0073 & -0.0889 & 0.1322 & 0.0094 & -0.0762 & 0.1058 & 0.0483 & 1.0000 \\
\hline \multicolumn{9}{|c|}{ Panel D: Results for Fukuoka (2001M04 - 2009M06) } \\
\hline Liu & 1.0000 & & & & & & & \\
\hline Price & -0.0233 & 1.0000 & & & & & & \\
\hline Volatility & 0.0280 & -0.1955 & 1.0000 & & & & & \\
\hline Volume & -0.8429 & -0.1541 & -0.1478 & 1.0000 & & & & \\
\hline MV & -0.4742 & 0.4338 & -0.3915 & 0.5779 & 1.0000 & & & \\
\hline Amihud & 0.4028 & -0.4875 & 0.6444 & -0.4378 & -0.6088 & 1.0000 & & \\
\hline Turnover & -0.6210 & -0.0024 & 0.1806 & 0.5102 & -0.1105 & -0.2520 & 1.0000 & \\
\hline Bid Ask Spread & 0.1098 & -0.3426 & 0.4529 & -0.1338 & -0.4112 & 0.4415 & 0.0633 & 1.0000 \\
\hline
\end{tabular}




\begin{tabular}{|c|c|c|c|c|c|c|c|c|}
\hline \multicolumn{9}{|c|}{ Panel E: Results for Sapporo (2001M04 - 2009M06) } \\
\hline & Liu & Price & Volatility & Volume & MV & Amihud & Turnover & Bid Ask Spread \\
\hline Liu & 1.0000 & & & & & & & \\
\hline Price & -4.5716 & 1.0000 & & & & & & \\
\hline Volatility & -1.2504 & -0.1851 & 1.0000 & & & & & \\
\hline Volume & -0.9950 & -0.3388 & -0.3811 & 1.0000 & & & & \\
\hline MV & -3.7821 & 0.3272 & -4.3448 & -1.5010 & 1.0000 & & & \\
\hline Amihud & -0.1008 & -0.5086 & 0.0964 & 0.3230 & -0.2543 & 1.0000 & & \\
\hline Turnover & -1.0583 & -0.1859 & -0.2135 & 0.6005 & -0.1568 & -0.3881 & 1.0000 & \\
\hline Bid Ask Spread & -1.1862 & -0.2244 & 0.0047 & 0.1011 & -0.3163 & -0.5677 & 0.0063 & 1.0000 \\
\hline
\end{tabular}


Table 4 Total costs on liquidity proxies and measures

\begin{tabular}{|c|c|c|c|c|c|c|c|c|c|c|}
\hline Market & $\mathbf{N}$ & Intercept & Price & Volatility & Volume & Size & Amihud & Liu & Turnover & Adj-R ${ }^{2}$ \\
\hline \multirow[t]{10}{*}{ Tokyo } & 44,928 & -0.36490 & -0.01560 & -0.00137 & 0.00128 & 0.03977 & & & & 0.931245 \\
\hline & & {$[-10.72]$} & {$[-2.06]$} & {$[-0.02]$} & {$[0.58]$} & [9.03] & & & & \\
\hline & & -0.36065 & -0.01583 & 0.00345 & 0.00088 & 0.03971 & -0.83765 & & & 0.931246 \\
\hline & & {$[-10.35]$} & {$[-2.11]$} & {$[0.05]$} & {$[0.35]$} & [9.01] & {$[-0.71]$} & & & \\
\hline & & -0.36693 & -0.01530 & -0.00832 & 0.00157 & 0.03959 & & 0.00095 & & 0.931254 \\
\hline & & {$[-10.63]$} & {$[-2.02]$} & {$[-0.14]$} & {$[0.71]$} & [8.99] & & {$[2.10]$} & & \\
\hline & & -0.37690 & -0.01730 & -0.00210 & 0.00080 & 0.04157 & & & 0.00400 & 0.931259 \\
\hline & & {$[-11.24]$} & {$[-2.31]$} & {$[-0.03]$} & {$[0.37]$} & [9.70] & & & {$[4.50]$} & \\
\hline & & -0.37408 & -0.01723 & -0.00369 & 0.00064 & 0.04130 & -0.94057 & 0.00096 & 0.00397 & 0.931270 \\
\hline & & {$[-10.94]$} & {$[-2.33]$} & {$[-0.06]$} & {$[0.26]$} & [9.64] & {$[-0.79]$} & {$[2.14]$} & [4.49] & \\
\hline \multirow[t]{10}{*}{ Osaka } & 25,623 & 0.07043 & -0.02616 & 0.39943 & -0.01907 & 0.01185 & & & & 0.379199 \\
\hline & & [6.92] & {$[-9.30]$} & {$[11.40]$} & {$[-14.66]$} & [7.27] & & & & \\
\hline & & 0.05386 & -0.02474 & 0.32889 & -0.01615 & 0.01171 & 0.05266 & & & 0.393593 \\
\hline & & [5.77] & {$[-8.84]$} & {$[9.71]$} & {$[-13.12]$} & [7.21] & [6.14] & & & \\
\hline & & 0.04555 & -0.02384 & 0.37810 & -0.01395 & 0.01066 & & 0.00087 & & 0.385383 \\
\hline & & [5.19] & {$[-8.44]$} & [11.02] & {$[-17.55]$} & [6.51] & & [5.54] & & \\
\hline & & 0.07022 & -0.02621 & 0.39929 & -0.01907 & 0.01189 & & & 0.00011 & 0.379183 \\
\hline & & [6.91] & {$[-9.24]$} & {$[11.41]$} & {$[-14.62]$} & [7.23] & & & [0.59] & \\
\hline & & 0.03022 & -0.02250 & 0.30946 & -0.01126 & 0.01053 & 0.05185 & 0.00083 & $-5.27 \mathrm{E}-05$ & 0.399308 \\
\hline & & [3.49] & {$[-8.00]$} & [9.41] & {$[-14.38]$} & [6.45] & [6.21] & [5.27] & {$[-0.43]$} & \\
\hline \multirow[t]{10}{*}{ Nagoya } & 8,811 & 0.09142 & -0.00874 & 0.26268 & -0.01119 & -0.00022 & & & & 0.626615 \\
\hline & & [10.34] & {$[-2.83]$} & [8.63] & {$[-13.07]$} & [-0.19] & & & & \\
\hline & & 0.09135 & -0.00901 & 0.26909 & -0.01142 & $-3.58 \mathrm{E}-05$ & -0.00180 & & & 0.626679 \\
\hline & & {$[10.42]$} & {$[-3.01]$} & [8.80] & {$[-13.03]$} & {$[-0.03]$} & {$[-1.05]$} & & & \\
\hline & & 0.09613 & -0.00806 & 0.26254 & -0.01112 & -0.00094 & & $6.45 \mathrm{E}-06$ & & 0.626585 \\
\hline & & [9.19] & {$[-2.53]$} & [8.63] & {$[-13.02]$} & {$[-0.65]$} & & [1.17] & & \\
\hline & & 0.09512 & -0.00793 & 0.26706 & -0.01102 & -0.00092 & & & -0.06918 & 0.626664 \\
\hline & & {$[10.26]$} & {$[-2.30]$} & [9.11] & {$[-13.13]$} & {$[-0.64]$} & & & [-1.15] & \\
\hline & & 0.10252 & -0.00709 & 0.27831 & -0.01114 & -0.00188 & -0.00185 & $9.79 \mathrm{E}-06$ & -0.07526 & 0.626716 \\
\hline & & [8.84] & {$[-1.95]$} & [9.33] & {$[-13.01]$} & {$[-1.05]$} & {$[-1.07]$} & [1.48] & {$[-1.23]$} & \\
\hline
\end{tabular}




\begin{tabular}{|c|c|c|c|c|c|c|c|c|c|c|}
\hline Market & $\mathbf{N}$ & Intercept & Price & Volatility & Volume & Size & Amihud & Liu & Turnover & Adj-R ${ }^{2}$ \\
\hline \multirow[t]{9}{*}{ Fukuoka } & 2,851 & $\begin{array}{c}-0.09352 \\
{[-0.81]}\end{array}$ & $\begin{array}{c}-0.10139 \\
{[-6.67]}\end{array}$ & $\begin{array}{c}0.35758 \\
{[7.21]}\end{array}$ & $\begin{array}{c}-0.01099 \\
{[-4.74]}\end{array}$ & $\begin{array}{c}0.04558 \\
{[2.95]}\end{array}$ & & & & 0.304389 \\
\hline & & -0.09208 & -0.09907 & 0.31033 & -0.00964 & 0.04419 & 0.01237 & & & 0.305281 \\
\hline & & {$[-0.80]$} & {$[-6.73]$} & {$[6.05]$} & {$[-4.55]$} & [2.91] & [1.07] & & & \\
\hline & & -0.06001 & -0.10108 & 0.35261 & -0.01470 & 0.04419 & & -0.00034 & & 0.304809 \\
\hline & & {$[-0.52]$} & {$[-6.66]$} & [7.12] & {$[-5.11]$} & [2.86] & & {$[-1.33]$} & & \\
\hline & & -0.07811 & -0.09875 & 0.36112 & -0.01075 & 0.04315 & & & -0.15797 & 0.304241 \\
\hline & & {$[-0.64]$} & {$[-5.92]$} & [7.20] & {$[-4.46]$} & {$[2.57]$} & & & {$[-0.89]$} & \\
\hline & & -0.04511 & -0.09639 & 0.30870 & -0.01308 & 0.04063 & 0.01235 & -0.00033 & -0.14258 & 0.305533 \\
\hline & & {$[-0.37]$} & {$[-5.96]$} & [5.87] & [-4.69] & [2.46] & [1.07] & {$[-1.32]$} & {$[-0.87]$} & \\
\hline \multirow[t]{9}{*}{ Sapporo } & 1,234 & $\begin{array}{c}0.43173 \\
{[3.95]}\end{array}$ & $\begin{array}{c}-0.05101 \\
{[-2.91]}\end{array}$ & $\begin{array}{c}0.04560 \\
{[5.02]}\end{array}$ & $\begin{array}{c}-0.01389 \\
{[-1.66]}\end{array}$ & $\begin{array}{c}-0.01139 \\
{[-1.28]}\end{array}$ & & & & 0.341672 \\
\hline & & 0.32173 & -0.04049 & 0.03242 & -0.01257 & -0.00613 & 0.01967 & & & 0.431223 \\
\hline & & [3.62] & {$[-2.80]$} & {$[5.31]$} & [-1.94] & {$[-0.84]$} & [4.96] & & & \\
\hline & & 0.36511 & -0.05085 & 0.04577 & -0.00487 & -0.00950 & & 0.00078 & & 0.342050 \\
\hline & & [4.09] & {$[-2.91]$} & {$[5.01]$} & {$[-0.33]$} & {$[-1.17]$} & & [1.04] & & \\
\hline & & 0.39217 & -0.05823 & 0.04526 & -0.01521 & -0.00461 & & & 0.35355 & 0.341603 \\
\hline & & {$[3.61]$} & {$[-3.24]$} & [4.99] & {$[-1.79]$} & {$[-0.49]$} & & & [2.18] & \\
\hline & & 0.25165 & -0.04552 & 0.03231 & -0.00777 & -0.00016 & 0.01963 & 0.00050 & 0.24986 & 0.430999 \\
\hline & & [3.38] & {$[-3.14]$} & {$[5.25]$} & {$[-0.61]$} & {$[-0.02]$} & [4.94] & [0.68] & {$[1.73]$} & \\
\hline
\end{tabular}




\section{Table 5 Likelihood ratio tests}

This table presents the results of the Vuong (1989) likelihood ratio test for non-nested model selection for each market. The models compared are based on the regressions of the bid-ask spread and Amihud measure, defined in Amihud (2002), Turnover, defined as a ratio of the traded volume of shares in relation to total number of shares outstanding and is scaled by the number of trading days in the month of measurement, Liu measure of liquidity, of Liu (2006) representing a standardized turnover-adjusted number of zero returns over the prior month. Natural logarithms are taken of Traded Volume, price, and market capitalisation variables which in addition to the volatility measure, defined as monthly average of daily stock returns, represent the underlying set of explanatory variables in Stoll (2000). A Z-statistic, using a one sided probability, is the basis of determining if the Amihud estimate or Turnover (the reference model) is better at explaining the true bid-ask spread data generating process than alternative liquidity proxies, or the comparison models tested either singularly or as a group. The group contains all the competing liquidity measures excluding the reference estimate.

\begin{tabular}{|c|c|c|c|c|c|c|c|c|}
\hline \multirow[t]{2}{*}{ Country } & \multirow[t]{2}{*}{$\mathbf{N}$} & \multicolumn{4}{|c|}{ Liu versus } & \multicolumn{3}{|c|}{ Amihud versus } \\
\hline & & Stoll & Turnover & Amihud & Group & Stoll & Turnover & Group \\
\hline Tokyo & 44,928 & -45.93 & $-105.39 *$ & $2.46^{*}$ & -1.38 & $-45.44 *$ & $-105.37 *$ & $-5.19^{*}$ \\
\hline Osaka & 25,623 & -13.78 & 9.38* & 0.12 & 0.11 & $-9.45^{*}$ & $11.75 *$ & -0.14 \\
\hline Nagoya & 8,811 & -11.38 & -0.25 & -1.54 & -1.69 & $-10.51 *$ & 1.52 & 1.40 \\
\hline Fukuoka & 2,851 & $-12.42 *$ & $3.59 \%$ & $-3.34^{*}$ & $-3.40^{*}$ & $-6.01 *$ & $4.89 *$ & $3.31 *$ \\
\hline Sapporo & 1,234 & $-6.63 *$ & $2.37 *$ & $-2.05 \dagger$ & $-2.07 \dagger$ & 0.44 & $2.16 \dagger$ & $2.05 \dagger$ \\
\hline
\end{tabular}

Notes: $(1) *$ Denotes significance at the $1 \%$ level

(2) $\dagger$ Denotes significance at the $5 \%$ level

(3) $\mathrm{Z}$ critical values at $90 \%, 95 \%$ and $99 \%$ confidence levels are $1.28,1.96$ and 2.33 


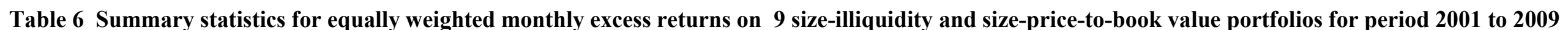

\begin{tabular}{|c|c|c|c|c|c|c|c|c|c|}
\hline Portfolio & $\mathbf{S} / \mathbf{L}$ & $\mathbf{S} / \mathbf{M}$ & $\mathbf{S} / \mathbf{H}$ & $\mathbf{M} / \mathbf{L}$ & $\mathbf{M} / \mathbf{M}$ & $\mathbf{M} / \mathbf{H}$ & $\mathbf{B} / \mathbf{L}$ & $\mathbf{B} / \mathbf{M}$ & $\mathbf{B} / \mathbf{H}$ \\
\hline \multicolumn{10}{|c|}{$\begin{array}{l}\text { Panel A: Portfolios sorted on Size- Price to Book Value } \\
\text { Summary statistics for portfolios }\end{array}$} \\
\hline Mean & 0.00215 & 0.00055 & 0.00051 & 0.00405 & 0.00538 & 0.00254 & 0.00342 & 0.00128 & 0.00395 \\
\hline Median & -0.00393 & -0.00272 & 0.00316 & 0.00059 & 0.00420 & 0.00018 & -0.00118 & 0.00231 & -0.00067 \\
\hline Std. Dev. & 0.05313 & 0.05257 & 0.05960 & 0.04938 & 0.05143 & 0.06199 & 0.05264 & 0.05616 & 0.07541 \\
\hline Skewness & 0.632 & 0.451 & 0.184 & 0.499 & 0.638 & 0.454 & 0.802 & 0.750 & 0.768 \\
\hline Excess Kurtosis & 3.905 & 3.440 & 2.856 & 4.765 & 4.184 & 3.246 & 4.785 & 5.361 & 4.261 \\
\hline Jarque-Bera statistic & $10.18(0.01)$ & $4.23(0.12)$ & $0.66(0.72)$ & $17.3(0.00)$ & $12.75(0.00)$ & $3.73(0.15)$ & $24.25(0.00)$ & $32.94(0.00)$ & $16.61(0.00)$ \\
\hline \multicolumn{10}{|c|}{$\begin{array}{l}\text { Panel B: Portfolios sorted on Size-illiquidity } \\
\text { Summary statistics for portfolios }\end{array}$} \\
\hline Mean & 0.00030 & 0.00083 & 0.00213 & 0.00714 & 0.00322 & 0.00236 & 0.00513 & 0.00094 & 0.00221 \\
\hline Median & -0.00059 & -0.00226 & 0.00005 & 0.00508 & -0.00045 & -0.00123 & -0.00471 & -0.00357 & 0.00143 \\
\hline Std. Dev. & 0.05547 & 0.05757 & 0.05165 & 0.05900 & 0.06267 & 0.04333 & 0.07638 & 0.05477 & 0.05225 \\
\hline Skewness & 0.161 & 0.435 & 0.699 & 0.319 & 0.361 & 0.742 & 0.679 & 0.576 & 0.932 \\
\hline Excess Kurtosis & 2.820 & 3.407 & 4.141 & 3.234 & 3.379 & 4.627 & 3.809 & 4.918 & 6.093 \\
\hline Jarque-Bera statistic & $0.57(0.75)$ & $3.88(0.14)$ & $13.72(0.00)$ & $1.94(0.38)$ & $2.8(0.25)$ & $20.4(0.00)$ & $10.51(0.01)$ & $21.06(0.00)$ & $54.89(0.00)$ \\
\hline \multicolumn{10}{|c|}{ Panel C: Average Number of stocks per size-illiquidity/Price to Book Value sorted portfolio } \\
\hline Tokyo & 0.00 & 0.00 & 4.58 & 40.81 & 57.91 & 53.82 & 93.72 & 95.59 & 93.28 \\
\hline Osaka & 55.69 & 64.94 & 59.92 & 26.00 & 17.88 & 25.19 & 1.00 & 0.00 & 0.00 \\
\hline Nagoya & 21.90 & 22.80 & 15.06 & 19.89 & 11.00 & 8.54 & 0.00 & 0.00 & 0.00 \\
\hline Fukuoka & 4.91 & 7.88 & 4.82 & 3.00 & 8.97 & 5.90 & 0.00 & 0.00 & 0.00 \\
\hline Sapporo & 7.00 & 0.00 & 5.77 & 3.00 & 1.00 & 1.00 & 0.00 & 0.00 & 0.00 \\
\hline Overall Mean & 89.50 & 95.61 & 90.16 & 92.69 & 96.76 & 94.45 & 94.72 & 95.59 & 93.28 \\
\hline \multicolumn{10}{|c|}{ Panel D: Summary statistics for markets portfolios and valuation factors } \\
\hline & Mean & Std. Dev. & Skewness & $\begin{array}{l}\text { Excess } \\
\text { Kurtosis }\end{array}$ & & Mean & Std. Dev. & Skewness & $\begin{array}{l}\text { Excess } \\
\text { Kurtosis }\end{array}$ \\
\hline Tokyo Topix 100 & 0.00194 & 0.05421 & 0.275 & 3.127 & SMB & -0.00857 & 0.11372 & 0.013 & 2.735 \\
\hline Tokyo Topix 500 & 0.00353 & 0.05515 & 0.404 & 3.428 & ILLIQ & -0.00942 & 0.07919 & 0.128 & 3.708 \\
\hline Osaka Top 50 & 0.00755 & 0.06026 & 0.434 & 3.609 & PBV & -0.00616 & 0.08876 & 0.415 & 2.734 \\
\hline Osaka & 0.00383 & 0.06700 & 0.644 & 4.475 & MARKET & 0.00270 & 0.05270 & 0.627 & 4.458 \\
\hline Nagoya Top 20 & 0.00396 & 0.04434 & 0.803 & 4.850 & & & & & \\
\hline Nagoya & -0.00065 & 0.04418 & 0.972 & 5.302 & & SMB & ILLIQ & PBV & MARKET \\
\hline Fukuoka Top 10 & -0.00246 & 0.03869 & 0.649 & 4.168 & SMB & 1.0000 & & & \\
\hline Fukuoka & -0.00101 & 0.03963 & 0.647 & 4.491 & ILLIQ & -0.1050 & 1.0000 & & \\
\hline Sapporo Top 5 & -0.00170 & 0.04811 & 1.291 & 6.478 & PBV & -0.2668 & -0.5728 & 1.0000 & \\
\hline Sapporo & -0.00242 & 0.05074 & 0.456 & 3.908 & MARKET & -0.1355 & -0.5037 & 0.3637 & 1.0000 \\
\hline
\end{tabular}


Table 7 Time series regressions using equally weighted monthly contemporaneous market excess returns for 9 portfolios formed on size and illiquidity for period: $\mathbf{2 0 0 2}-\mathbf{2 0 0 8}$, for all sample markets.

\begin{tabular}{|c|c|c|c|c|c|c|c|c|c|}
\hline Portfolio & $\mathbf{S} / \mathbf{L}$ & $\mathbf{S} / \mathbf{M}$ & $\mathbf{S} / \mathbf{H}$ & $\mathbf{M} / \mathbf{L}$ & $\mathbf{M} / \mathbf{M}$ & $\mathbf{M} / \mathbf{H}$ & $\mathbf{B} / \mathbf{L}$ & $\mathbf{B} / \mathbf{M}$ & $\mathbf{B} / \mathbf{H}$ \\
\hline \multicolumn{10}{|c|}{$\begin{array}{l}\text { Panel A: Size-Price to Book Value } \\
\text { CAPM-adjusted performance }\end{array}$} \\
\hline$\alpha \%)$ & $\begin{array}{c}-0.000345 \\
(-0.18)\end{array}$ & $\begin{array}{c}-0.001916 \\
(-0.85)\end{array}$ & $\begin{array}{c}-0.002170 \\
(-0.63)\end{array}$ & $\begin{array}{l}0.001662 \\
(1.03)\end{array}$ & $\begin{array}{l}0.002819 \\
(2.17)\end{array}$ & $\begin{array}{c}-0.000384 \\
(-0.20)\end{array}$ & $\begin{array}{c}0.000973 \\
(0.48)\end{array}$ & $\begin{array}{c}-0.001400 \\
(-0.64)\end{array}$ & $\begin{array}{l}0.000584 \\
(0.15)\end{array}$ \\
\hline$\hat{\beta}$ & $\begin{array}{c}0.923673 \\
(15.79\end{array}$ & $\begin{array}{l}0.913772 \\
(21.15)\end{array}$ & $\begin{array}{l}0.995553 \\
(15.70)\end{array}$ & $\begin{array}{l}0.884778 \\
(26.11)\end{array}$ & $\begin{array}{l}0.948532 \\
(42.96)\end{array}$ & $\begin{array}{c}1.082769 \\
(25.58)\end{array}$ & $\begin{array}{c}0.908116 \\
(19.49)\end{array}$ & $\begin{array}{l}0.993823 \\
(22.79)\end{array}$ & $\begin{array}{c}1.247503 \\
(11.30)\end{array}$ \\
\hline $\operatorname{Adj} R^{2}(1)$ & 0.837674 & 0.837458 & 0.772713 & 0.890607 & 0.944255 & 0.845740 & 0.824847 & 0.868286 & 0.757679 \\
\hline \multicolumn{10}{|c|}{ Three-factor Fama and French (1993) CAPM performance } \\
\hline$\hat{\alpha}$ & $\begin{array}{c}-0.000157 \\
(-0.16)\end{array}$ & $\begin{array}{c}-0.000643 \\
(-0.67)\end{array}$ & $\begin{array}{l}0.000557 \\
(0.51)\end{array}$ & $\begin{array}{l}0.000318 \\
(0.28)\end{array}$ & $\begin{array}{l}0.002635 \\
(2.48)\end{array}$ & $\begin{array}{l}0.000561 \\
(0.45)\end{array}$ & $\begin{array}{c}-0.001473 \\
(-1.42)\end{array}$ & $\begin{array}{c}-0.003183 \\
(-2.68)\end{array}$ & $\begin{array}{l}0.001140 \\
(0.92)\end{array}$ \\
\hline$\hat{\beta}$ & $\begin{array}{c}1.027293 \\
(42.52)\end{array}$ & $\begin{array}{l}0.967922 \\
(42.73)\end{array}$ & $\begin{array}{l}0.993472 \\
(62.66)\end{array}$ & $\begin{array}{c}0.967497 \\
(38.72)\end{array}$ & $\begin{array}{l}0.991420 \\
(46.61)\end{array}$ & $\begin{array}{l}0.943254 \\
(24.86)\end{array}$ & $\begin{array}{l}0.975310 \\
(36.63)\end{array}$ & $\begin{array}{c}1.010272 \\
(26.89)\end{array}$ & $\begin{array}{c}1.029733 \\
(34.78)\end{array}$ \\
\hline$\hat{s}$ & $\begin{array}{c}0.131146 \\
(13.17)\end{array}$ & $\begin{array}{c}0.170523 \\
(18.70)\end{array}$ & $\begin{array}{c}0.234563 \\
(20.71)\end{array}$ & $\begin{array}{c}-0.025080 \\
(-2.53)\end{array}$ & $\begin{array}{l}0.031555 \\
(3.04)\end{array}$ & $\begin{array}{c}-0.072434 \\
(-5.97)\end{array}$ & $\begin{array}{c}-0.138011 \\
(-14.54)\end{array}$ & $\begin{array}{c}-0.136612 \\
(-13.22)\end{array}$ & $\begin{array}{c}-0.192950 \\
(-13.91)\end{array}$ \\
\hline$\hat{h}$ & $\begin{array}{c}-0.106546 \\
(-6.12)\end{array}$ & $\begin{array}{c}-0.006978 \\
(-0.63)\end{array}$ & $\begin{array}{c}0.115401 \\
(5.20)\end{array}$ & $\begin{array}{c}-0.147019 \\
(-6.84)\end{array}$ & $\begin{array}{c}-0.054950 \\
(-3.73)\end{array}$ & $\begin{array}{c}0.193179 \\
(7.45)\end{array}$ & $\begin{array}{c}-0.175599 \\
(-9.19)\end{array}$ & $\begin{array}{c}-0.092086 \\
(-5.896)\end{array}$ & $\begin{array}{c}0.263389 \\
(13.18)\end{array}$ \\
\hline $\operatorname{Adj} R^{2}(4)$ & 0.964812 & 0.973890 & 0.962689 & 0.947358 & 0.959048 & 0.945355 & 0.950035 & 0.943895 & 0.964825 \\
\hline \multicolumn{10}{|c|}{$\begin{array}{l}\text { Panel B: Size-Illiquidity } \\
\text { CAPM-adjusted performance }\end{array}$} \\
\hline$\alpha \%)$ & $\begin{array}{c}-0.002161 \\
(-0.69)\end{array}$ & $\begin{array}{c}-0.001891 \\
(-0.81)\end{array}$ & $\begin{array}{c}-0.000328 \\
(-0.20)\end{array}$ & $\begin{array}{l}0.004275 \\
(1.95)\end{array}$ & $\begin{array}{l}0.000205 \\
(0.11)\end{array}$ & $\begin{array}{c}0.000462 \\
(0.17)\end{array}$ & $\begin{array}{c}0.001687 \\
(0.44)\end{array}$ & $\begin{array}{c}-0.001679 \\
(-0.80)\end{array}$ & $\begin{array}{c}-0.000156 \\
(-0.07)\end{array}$ \\
\hline$\hat{\beta}$ & $\begin{array}{c}0.912889 \\
(12.90)\end{array}$ & $\begin{array}{c}1.008984 \\
(18.28)\end{array}$ & $\begin{array}{l}0.909782 \\
(25.45)\end{array}$ & $\begin{array}{l}1.064217 \\
(21.53)\end{array}$ & $\begin{array}{c}1.117341 \\
(29.98)\end{array}$ & $\begin{array}{c}0.705194 \\
(17.15)\end{array}$ & $\begin{array}{c}1.276401 \\
(14.17)\end{array}$ & $\begin{array}{c}0.972594 \\
(21.28)\end{array}$ & $\begin{array}{c}0.878421 \\
(14.91)\end{array}$ \\
\hline $\begin{array}{l}\text { Adj } R^{2}(1) \\
\text { Three-facto }\end{array}$ & $\begin{array}{l}0.749612 \\
\text { and Illiquidity }\end{array}$ & $\begin{array}{l}0.851510 \\
\text { PM performa }\end{array}$ & 0.860157 & 0.902612 & 0.881629 & 0.732949 & 0.773382 & 0.874636 & 0.782753 \\
\hline$\hat{\alpha}$ & $\begin{array}{c}-0.001191 \\
(-1.35)\end{array}$ & $\begin{array}{c}-0.000780 \\
(-1.18)\end{array}$ & $\begin{array}{c}0.001298 \\
(1.39)\end{array}$ & $\begin{array}{c}0.004623 \\
(2.97)\end{array}$ & $\begin{array}{c}-0.001185 \\
(-0.84)\end{array}$ & $\begin{array}{c}0.001912 \\
(1.25)\end{array}$ & $\begin{array}{c}-0.001191 \\
(-1.35)\end{array}$ & $\begin{array}{c}-0.000780 \\
(-1.18)\end{array}$ & $\begin{array}{c}0.001298 \\
(1.39)\end{array}$ \\
\hline$\hat{\beta}$ & $\begin{array}{c}0.906645 \\
(49.61)\end{array}$ & $\begin{array}{c}1.035254 \\
(64.97)\end{array}$ & $\begin{array}{c}1.003524 \\
(40.89)\end{array}$ & $\begin{array}{c}1.054200 \\
(35.10)\end{array}$ & $\begin{array}{c}1.024667 \\
(27.41)\end{array}$ & $\begin{array}{c}0.871998 \\
(20.86)\end{array}$ & $\begin{array}{c}0.906645 \\
(49.61)\end{array}$ & $\begin{array}{c}1.035254 \\
(64.97)\end{array}$ & $\begin{array}{c}1.003524 \\
(40.89)\end{array}$ \\
\hline$\hat{s}$ & $\begin{array}{c}0.208984 \\
(24.99)\end{array}$ & $\begin{array}{c}0.173274 \\
(19.32)\end{array}$ & $\begin{array}{c}0.144468 \\
(15.40)\end{array}$ & $\begin{array}{c}0.090401 \\
(7.48)\end{array}$ & $\begin{array}{c}-0.098691 \\
(-4.80)\end{array}$ & $\begin{array}{c}-0.035602 \\
(-2.73)\end{array}$ & $\begin{array}{c}0.208984 \\
(24.99)\end{array}$ & $\begin{array}{c}0.173274 \\
(19.32)\end{array}$ & $\begin{array}{c}0.144468 \\
(15.40)\end{array}$ \\
\hline$\hat{h}$ & $\begin{array}{c}-0.089014 \\
(-5.26)\end{array}$ & $\begin{array}{c}-0.032253 \\
(-1.76)\end{array}$ & $\begin{array}{c}0.068031 \\
(3.77)\end{array}$ & $\begin{array}{c}-0.048172 \\
(-1.70)\end{array}$ & $\begin{array}{c}-0.084311 \\
(-2.24)\end{array}$ & $\begin{array}{c}0.234156 \\
(7.18)\end{array}$ & $\begin{array}{c}-0.089014 \\
(-5.26)\end{array}$ & $\begin{array}{c}-0.032253 \\
(-1.76)\end{array}$ & $\begin{array}{c}0.068031 \\
(3.77)\end{array}$ \\
\hline $\operatorname{Adj} R^{2}(4)$ & 0.962080 & 0.973941 & 0.956172 & 0.938572 & 0.913562 & 0.891478 & 0.962080 & 0.973941 & 0.956172 \\
\hline
\end{tabular}

Notes: (1) Numbers in parentheses are t-statistics.

(2) One month T-bill risk free rate for month t, which is taken as the one month UK Gilt rate in this case 


\begin{tabular}{|c|c|c|c|c|c|}
\hline & $\hat{\alpha}$ & $\hat{\beta}$ & $\hat{s}$ & $\hat{h}$ & $\operatorname{Adj} R^{2}$ \\
\hline \multicolumn{6}{|l|}{ Panel A: Tokyo TOPIX 100} \\
\hline CAPM & $-0.000507(-0.17)$ & $0.907495(13.57)$ & & & 0.776116 \\
\hline CAPM + SMB & $0.001101(1.17)$ & $0.967937(40.12)$ & $0.206652(23.80)$ & & 0.962100 \\
\hline CAPM + ILLIQ & $-0.001336(-0.49)$ & $0.822400(12.19)$ & & $-0.112435(-2.96)$ & 0.794378 \\
\hline $\mathrm{CAPM}+\mathrm{SMB}+$ ILLIQ & $0.000723(0.83)$ & $0.931947(39.55)$ & $0.201072(19.80)$ & $-0.045398(-2.64)$ & 0.964955 \\
\hline \multicolumn{6}{|l|}{ Panel B: Tokyo TOPIX 500} \\
\hline CAPM & $0.000869(0.44)$ & $0.988113(22.53)$ & & & 0.890355 \\
\hline $\mathrm{CAPM}+\mathrm{SMB}$ & $0.002075(4.03)$ & $1.033464(98.32)$ & $0.155053(36.43)$ & & 0.991627 \\
\hline CAPM + ILLIQ & $0.000401(0.21)$ & $0.940102(20.73)$ & & $-0.063436(-2.34)$ & 0.895555 \\
\hline $\mathrm{CAPM}+\mathrm{SMB}+$ ILLIQ & $0.001973(4.09)$ & $1.023757(85.96)$ & $0.153548(33.42)$ & $-0.012243(-1.04)$ & 0.991768 \\
\hline \multicolumn{6}{|l|}{ Panel C: Osaka Top 50} \\
\hline CAPM & $0.004678(2.74)$ & $1.063578(20.36)$ & & & 0.863809 \\
\hline $\mathrm{CAPM}+\mathrm{SMB}$ & $0.004084(2.25)$ & $1.041255(16.12)$ & $-0.076322(-3.57)$ & & 0.883200 \\
\hline CAPM + ILLIQ & $0.004585(2.65)$ & $1.054057(16.78)$ & & $-0.012580(-0.33)$ & 0.862627 \\
\hline $\mathrm{CAPM}+\mathrm{SMB}+$ ILLIQ & $0.003754(2.02)$ & $1.009821(12.77)$ & $-0.081195(-3.82)$ & $-0.039650(-1.08)$ & 0.884000 \\
\hline \multicolumn{6}{|l|}{ Panel D: Osaka } \\
\hline CAPM & $0.000607(0.28)$ & $1.195687(20.19)$ & & & 0.883348 \\
\hline CAPM + SMB & $-0.000786(-0.71)$ & $1.143321(65.19)$ & $-0.179039(-15.54)$ & & 0.974666 \\
\hline CAPM + ILLIQ & $0.000345(0.15)$ & $1.168821(16.61)$ & & $-0.035498(-1.01)$ & 0.883499 \\
\hline $\mathrm{CAPM}+\mathrm{SMB}+$ ILLIQ & $-0.001613(-1.90)$ & $1.064632(65.87)$ & $-0.191239(-21.11)$ & $-0.099257(-5.68)$ & 0.984561 \\
\hline \multicolumn{6}{|l|}{ Panel E: Nagoya Top 20} \\
\hline CAPM & $0.002028(0.79)$ & $0.717489(16.34)$ & & & 0.724488 \\
\hline $\mathrm{CAPM}+\mathrm{SMB}$ & $0.001701(0.70)$ & $0.705166(15.42)$ & $-0.042134(-2.20)$ & & 0.733376 \\
\hline CAPM + ILLIQ & $0.003561(1.95)$ & $0.874840(17.78)$ & & $0.207906(5.16)$ & 0.826688 \\
\hline $\mathrm{CAPM}+\mathrm{SMB}+$ ILLIQ & $0.003384(1.85)$ & $0.865421(16.52)$ & $-0.017288(-0.93)$ & $0.202142(4.78)$ & 0.826809 \\
\hline \multicolumn{6}{|l|}{ Panel F: Nagoya } \\
\hline CAPM & $-0.002656(-1.11)$ & $0.742317(20.57)$ & & & 0.781666 \\
\hline $\mathrm{CAPM}+\mathrm{SMB}$ & $-0.003419(-1.89)$ & $0.713614(22.29)$ & $-0.098135(-6.96)$ & & 0.843340 \\
\hline CAPM + ILLIQ & $-0.001104(-0.74)$ & $0.901534(29.64)$ & & $0.210372(10.50)$ & 0.887700 \\
\hline $\mathrm{CAPM}+\mathrm{SMB}+\mathrm{ILLIQ}$ & $-0.001876(-1.67)$ & $0.860474(28.35)$ & $-0.075366(-6.86)$ & $0.185245(11.19)$ & 0.923060 \\
\hline \multicolumn{6}{|l|}{ Panel G: Fukuoka Top 10} \\
\hline CAPM & $-0.003580(-0.91)$ & $0.415684(5.94)$ & & & 0.313778 \\
\hline CAPM + SMB & $-0.003695(-0.96)$ & $0.411343(5.65)$ & $-0.014840(-0.48)$ & & 0.308682 \\
\hline CAPM + ILLIQ & $-0.001775(-0.55)$ & $0.600946(5.73)$ & & $0.244786(3.73)$ & 0.497989 \\
\hline $\mathrm{CAPM}+\mathrm{SMB}+\mathrm{ILLIQ}$ & $-0.001612(-0.49)$ & $0.609608(5.99)$ & $0.015899(0.50)$ & $0.250087(3.82)$ & 0.494934 \\
\hline
\end{tabular}




\begin{tabular}{|c|c|c|c|c|c|}
\hline & $\hat{\alpha}$ & $\hat{\beta}$ & $\hat{S}$ & $\hat{h}$ & $\operatorname{Adj} R^{2}$ \\
\hline \multicolumn{6}{|l|}{ Panel H: Fukuoka } \\
\hline CAPM & $-0.002423(-0.66)$ & $0.525261(8.97)$ & & & 0.482585 \\
\hline $\mathrm{CAPM}+\mathrm{SMB}$ & $-0.002942(-0.88)$ & $0.505752(7.80)$ & $-0.066700(-3.59)$ & & 0.513992 \\
\hline CAPM + ILLIQ & $-0.000491(-0.18)$ & $0.723521(10.20)$ & & $0.261960(5.44)$ & 0.685935 \\
\hline $\mathrm{CAPM}+\mathrm{SMB}+\mathrm{ILLIQ}$ & $-0.000860(-0.32)$ & $0.703922(8.84)$ & $-0.035975(-1.74)$ & $0.249966(5.04)$ & 0.693038 \\
\hline \multicolumn{6}{|l|}{ Panel I: Sapporo Top 5} \\
\hline CAPM & $-0.002805(-0.65)$ & $0.409407(3.88)$ & & & 0.193016 \\
\hline CAPM + SMB & $-0.002937(-0.70)$ & $0.404423(3.63)$ & $-0.017040(-0.49)$ & & 0.186406 \\
\hline CAPM + ILLIQ & $-0.000692(-0.17)$ & $0.626232(5.10)$ & & $0.286488(4.25)$ & 0.354111 \\
\hline $\mathrm{CAPM}+\mathrm{SMB}+$ ILLIQ & $-0.000498(-0.12)$ & $0.636556(4.92)$ & $0.018950(0.57)$ & $0.292806(4.21)$ & 0.349399 \\
\hline \multicolumn{6}{|l|}{ Panel J: Sapporo } \\
\hline CAPM & $-0.004152(-1.04)$ & $0.641276(8.30)$ & & & 0.438011 \\
\hline CAPM + SMB & $-0.004960(-1.36)$ & $0.610925(6.87)$ & $-0.103769(-3.16)$ & & 0.486462 \\
\hline CAPM + ILLIQ & $-0.002280(-0.62)$ & $0.833494(9.34)$ & & $0.253976(3.88)$ & 0.551941 \\
\hline $\mathrm{CAPM}+\mathrm{SMB}+\mathrm{ILLIQ}$ & $-0.003054(-0.85)$ & $0.792278(7.22)$ & $-0.075652(-2.68)$ & $0.228754(3.55)$ & 0.575226 \\
\hline
\end{tabular}


Table 9 Time varying CAPM model parameters

\begin{tabular}{|c|c|c|c|c|c|c|c|c|c|c|c|}
\hline Country & & $\begin{array}{l}\text { Overall } \\
\text { Mean }\end{array}$ & $\begin{array}{c}\text { Overall High/ } \\
\text { low }\end{array}$ & 2002 & 2003 & 2004 & 2005 & 2006 & 2007 & 2008 & $\begin{array}{c}\text { Convergence } \\
\text { (Iterations) }\end{array}$ \\
\hline Tokyo TOPIX & Constant & -0.00075 & $0.0158 /-0.0208$ & 0.00090 & -0.00412 & -0.00053 & 0.00140 & 0.00190 & 0.00098 & -0.00537 & \multirow[t]{4}{*}{24} \\
\hline \multirow[t]{3}{*}{100} & Market Beta & 0.967588 & $1.0043 / 0.8987$ & 1.04831 & 1.02117 & 0.95657 & 0.91542 & 0.92926 & 0.93984 & 0.97257 & \\
\hline & Size Beta & 0.196046 & $0.2461 / 0.1395$ & 0.18127 & 0.16489 & 0.16408 & 0.22168 & 0.23295 & 0.20251 & 0.20576 & \\
\hline & $\begin{array}{l}\text { Illiquidity } \\
\text { Beta }\end{array}$ & -0.03678 & $0.1344 /-0.3734$ & 0.04293 & -0.03916 & 0.00615 & -0.17585 & -0.02406 & -0.04534 & -0.04646 & \\
\hline \multirow{4}{*}{$\begin{array}{l}\text { Tokyo TOPIX } \\
500\end{array}$} & Constant & 0.000647 & $0.0495 /-0.0371$ & 0.00283 & -0.00580 & -0.00639 & 0.00120 & 0.00803 & 0.00688 & -0.00033 & \multirow[t]{4}{*}{22} \\
\hline & Market Beta & 0.937359 & $1.1184 / 0.7294$ & 1.03152 & 1.12276 & 0.94834 & 0.88669 & 0.85593 & 0.85598 & 0.81912 & \\
\hline & Size Beta & -- -- & -- -- & -- -- & -- -- & -- -- & -- -- & -- -- & -- -- & -- -- & \\
\hline & $\begin{array}{l}\text { Illiquidity } \\
\text { Beta }\end{array}$ & -0.02728 & $0.1241 /-0.2145$ & -0.00043 & -0.10514 & 0.01863 & -0.05857 & -0.03413 & 0.08119 & -0.05688 & \\
\hline \multirow[t]{4}{*}{ Osaka Top 50} & Constant & 0.004457 & $0.0599 /-0.0332$ & -0.00916 & 0.01932 & -0.00013 & 0.01011 & 0.00332 & 0.00992 & -0.00282 & \multirow[t]{4}{*}{16} \\
\hline & Market Beta & 1.01428 & $1.1147 / 0.9081$ & 0.98566 & 0.88432 & 0.97131 & 1.00434 & 1.06583 & 1.04796 & 1.09698 & \\
\hline & Size Beta & -- -- & -- -- & -- -- & -- -- & -- -- & -- -- & -- -- & -- -- & -- -- & \\
\hline & $\begin{array}{l}\text { Illiquidity } \\
\text { Beta }\end{array}$ & -- -- & -- -- & -- -- & -- -- & -- -- & -- -- & -- -- & -- -- & -- -- & \\
\hline \multirow[t]{4}{*}{ Osaka } & Constant & $-8.8 \mathrm{E}-05$ & $0.0231 /-0.0367$ & -0.00027 & 0.00294 & -0.00319 & -0.00300 & 0.00440 & 0.00684 & -0.00806 & \multirow[t]{4}{*}{15} \\
\hline & Market Beta & 1.172616 & $1.5882 / 1.0446$ & 1.14339 & 1.03750 & 1.11803 & 1.15464 & 1.18602 & 1.22053 & 1.36271 & \\
\hline & Size Beta & -0.20575 & $-0.1226 /-0.2719$ & -0.17239 & -0.17541 & -0.24286 & -0.25677 & -0.21295 & -0.21639 & -0.18134 & \\
\hline & $\begin{array}{l}\text { Illiquidity } \\
\text { Beta }\end{array}$ & -- -- & -- -- & -- -- & -- -- & -- -- & -- -- & -- -- & -- -- & -- -- & \\
\hline \multirow[t]{4}{*}{ Nagoya Top 20} & Constant & 0.00016 & $0.0743 /-0.0376$ & -0.00201 & 0.00311 & 0.00732 & -0.00945 & -0.01484 & -0.00013 & 0.01709 & \multirow[t]{4}{*}{16} \\
\hline & Market Beta & 0.722048 & $1.1607 / 0.2683$ & 0.79363 & 0.64015 & 0.78340 & 1.07573 & 0.55154 & 0.64174 & 0.54574 & \\
\hline & Size Beta & -0.00563 & $0.1495 /-0.159$ & -0.07380 & -0.01172 & -0.02703 & -0.02109 & 0.03072 & 0.10707 & -0.03938 & \\
\hline & $\begin{array}{l}\text { Illiquidity } \\
\text { Beta }\end{array}$ & -- -- & -- -- & -- -- & -- -- & -- -- & -- -- & -- -- & -- -- & -- -- & \\
\hline \multirow[t]{4}{*}{ Nagoya } & Constant & -- -- & -- -- & -- -- & -- -- & -- -- & -- -- & -- -- & -- -- & -- -- & \multirow{4}{*}{$\begin{array}{l}\text { Failed } \\
\text { converge }\end{array}$} \\
\hline & Market Beta & -- -- & -- -- & -- -- & -- -- & -- -- & -- -- & -- -- & -- -- & -- -- & \\
\hline & Size Beta & -- -- & -- -- & -- -- & -- -- & -- -- & -- -- & -- -- & -- -- & -- -- & \\
\hline & $\begin{array}{l}\text { Illiquidity } \\
\text { Beta }\end{array}$ & -- -- & -- -- & -- -- & -- -- & -- -- & -- -- & -- -- & -- -- & -- -- & \\
\hline
\end{tabular}




\begin{tabular}{|c|c|c|c|c|c|c|c|c|c|c|c|}
\hline \multirow[t]{5}{*}{ Fukuoka Top 10} & Constant & -0.0004 & $0.052 /-0.0514$ & -0.00803 & 0.00332 & -0.00094 & -0.00614 & -0.01023 & 0.00589 & 0.01359 & \multirow[t]{5}{*}{39} \\
\hline & Market Beta & 0.577045 & $1.1715 / 0.0624$ & 0.66447 & 0.37237 & 0.24397 & 0.39183 & 0.53236 & 0.76603 & 0.92024 & \\
\hline & Size Beta & -- -- & -- -- & -- -- & -- -- & -- -- & -- -- & -- -- & -- -- & -- -- & \\
\hline & Illiquidity & -0.13205 & $0.489 /-0.0373$ & 0.02484 & -0.04286 & 0.01244 & 0.04547 & 0.07371 & 0.29029 & 0.40321 & \\
\hline & Beta & & & & & & & & & & \\
\hline \multirow[t]{5}{*}{ Fukuoka } & Constant & -0.00209 & $0.0653 /-0.0413$ & -0.00883 & 0.00004 & -0.00433 & 0.00002 & -0.01476 & -0.00567 & 0.01209 & \multirow[t]{5}{*}{52} \\
\hline & Market Beta & 0.616249 & $0.9388 / 0.4109$ & 0.68277 & 0.54507 & 0.49312 & 0.49140 & 0.59113 & 0.65981 & 0.72219 & \\
\hline & Size Beta & -0.03835 & $0.0328 /-0.0811$ & -0.13322 & -0.03301 & -0.05891 & -0.03076 & 0.02388 & -0.02703 & -0.03062 & \\
\hline & Illiquidity & -0.1451 & $0.3771 / 0.0025$ & 0.12871 & 0.07781 & 0.08190 & 0.09513 & 0.07351 & 0.15730 & 0.30150 & \\
\hline & Beta & & & & & & & & & & \\
\hline \multirow[t]{5}{*}{ Sapporo Top 5} & Constant & -0.00293 & $0.0759 /-0.0999$ & -0.00375 & 0.00293 & -0.00396 & -0.01651 & -0.02499 & -0.01137 & 0.01923 & \multirow[t]{5}{*}{48} \\
\hline & Market Beta & 0.605925 & $0.6918 / 0.3794$ & 0.68601 & 0.45516 & 0.54650 & 0.57135 & 0.64615 & 0.60981 & 0.62352 & \\
\hline & Size Beta & 0.013112 & $0.159 /-0.0418$ & -0.11747 & -0.08736 & 0.02582 & 0.00755 & 0.13072 & 0.08758 & 0.03152 & \\
\hline & Illiquidity & -0.22218 & $0.8607 /-0.6408$ & 0.18892 & -0.00251 & 0.22818 & 0.16275 & 0.20500 & 0.27908 & 0.47642 & \\
\hline & Beta & & & & & & & & & & \\
\hline \multirow[t]{4}{*}{ Sapporo } & Constant & -0.00613 & $0.0709 /-0.0697$ & -0.00758 & -0.00452 & -0.00473 & 0.01014 & -0.01722 & -0.01887 & -0.00292 & \multirow[t]{4}{*}{37} \\
\hline & Market Beta & 0.644177 & $0.8226 / 0.4572$ & 0.48461 & 0.62696 & 0.62281 & 0.55478 & 0.62754 & 0.70199 & 0.68645 & \\
\hline & Size Beta & -0.08719 & $-0.0192 /-0.1422$ & -0.16196 & -0.12118 & -0.12817 & -0.09861 & -0.03637 & -0.06803 & -0.03951 & \\
\hline & $\begin{array}{l}\text { Illiquidity } \\
\text { Beta }\end{array}$ & -0.16539 & $0.6186 /-0.824$ & 0.11342 & 0.30913 & 0.24934 & -0.07311 & -0.10963 & 0.12583 & 0.35614 & \\
\hline
\end{tabular}

Notes: Means calculated both annually and across entire sample period. High/ Low values given for the entire sample period 
Table 10 Cost of Equity estimates derived from multi-factor regression (original)

Regression Cost of Equity Time varying coefficient Cost

Panel A: Top stocks

(\%) of Equity (\%)

Tokyo TOPIX 100

2.82

6.37

Osaka Top 50

4.94

7.68

Nagoya Top 20

6.43

5.87

Fukuoka Top 10

5.78

6.52

Sapporo Top 5

6.30

7.70

Panel B: Overall

Tokyo TOPIX 500

3.24

7.53

Osaka

5.56

10.23

Nagoya

6.80

Fukuoka

6.60

$--$

Sapporo

7.05

7.21

8.00

Notes: (1) Annualized cost of equity estimates generated at 12/2008 from the total risk premium

(2) The UK Gilt/ Treasury 1 Month rate is used in each case for risk free rate 


\section{Figure 1. Time varying liquidity beta for Tokyo (TOPIX500)}

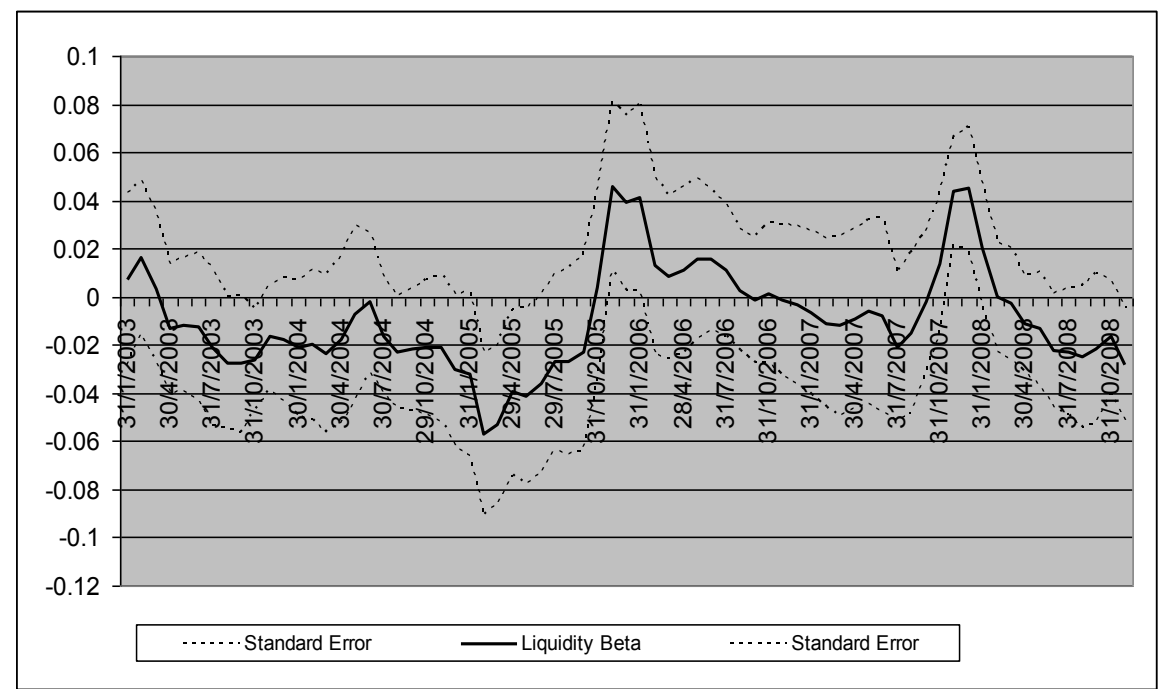

\section{Figure 3. Time varying liquidity beta for Sapporo}

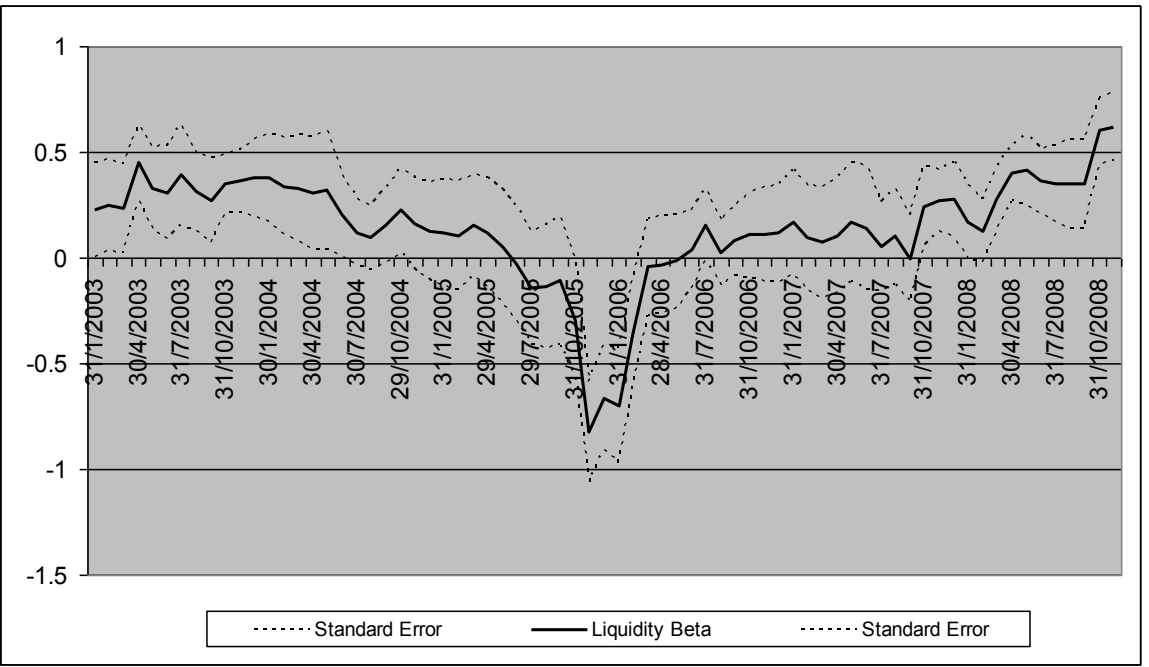

Figure 2. Time varying liquidity beta for Fukuoka

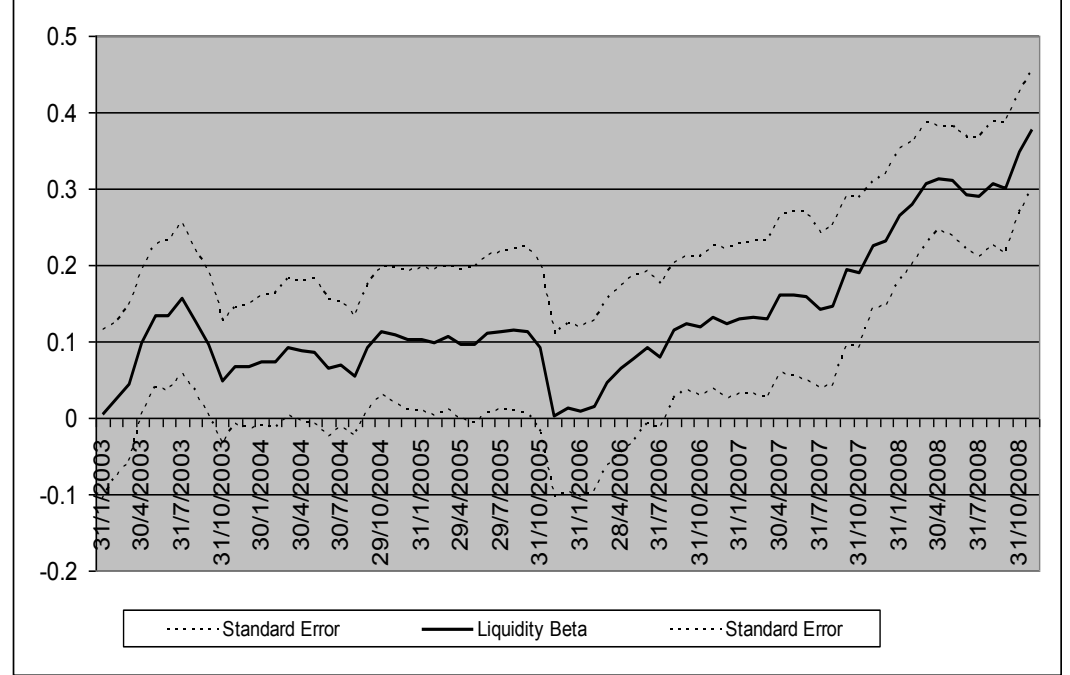




\section{Appendix 1. Vuong likelihood ratio test}

Following Lesmond (2005) a likelihood ratio test is used that was originally proposed by Vuong (1989). This is specific for non-nested model selection in testing whether a reference model and comparison model do equally well at explaining the underlying data. The reference model is either the Amihud measure (Amihud 2002) or alternatively the Turnover measure, which is a measure of trading frequency, and the comparison models are the remaining liquidity measures, i.e. Liu derived from Liu (2006) and the liquidity determinants of Stoll (2000). Each of the comparison models are tested independently against the reference Amihud or Turnover measure with each individual regression stated as:

Reference Model: $\quad \mathrm{S}+\mathrm{C}_{\mathrm{j}}=\theta_{0}+\theta_{1}\left(\right.$ reference liquidity measure $\left.\mathrm{j}_{\mathrm{j}}\right)+\varepsilon_{\mathrm{j}}$,

Comparison Model 1: $\mathrm{S}+\mathrm{C}_{\mathrm{j}}=\gamma_{0}+\gamma_{1}$ other liquidity measure $(\mathrm{s})_{\mathrm{j}}+\varepsilon_{\mathrm{j}}$, and

Comparison Model 2: $\mathrm{S}+\mathrm{C}_{\mathrm{j}}=\gamma_{0}+\gamma_{1}$ price $_{\mathrm{j}}+\gamma_{2}$ volume $_{\mathrm{j}}+\gamma_{3} \sigma_{\mathrm{j}}^{2}+\gamma_{4}$ size $_{\mathrm{j}}+\varepsilon_{\mathrm{j}}$,

where $\mathrm{S}+\mathrm{C}_{\mathrm{j}}$ refers to the average, proportional bid ask spread plus commission cost for each firm-month $\mathrm{j}$ within each country. The comparison liquidity measures are those of Liu (2006). Price is the average annual daily stock price in local currency, and volume is the average annual daily trading volume. $\sigma_{j}^{2}$ is the daily average volatility. Size is the monthly market capitalization and is defined as the share price times the number of shares outstanding. Share price is measured at the beginning of each month, while number of shares outstanding is measured at the beginning of the year.

The basis of the test is a likelihood ratio of the log likelihood function for the reference model to the $\log$ likelihood function for the comparison model. Using $\mathrm{R}$ to represent the reference model and $\mathrm{C}$ to represent the comparison model:

$$
L R_{n} \theta \gamma_{-} \equiv L_{n}^{R} \theta_{-} L_{n}^{C} \gamma_{-}=\sum_{i=1}^{n} \log \frac{f \boldsymbol{\$}+C \mid Z_{i} ; \theta}{g+C \mid Z_{i} ; \gamma_{-}},
$$

Where $\mathrm{LR}_{\mathrm{n}}$ is the likelihood ratio function for $\mathrm{n}$ firm-month observations in each country. $Z_{\mathrm{i}}$ is a vector of $\mathrm{m}$ independent standard normal variables, $\hat{\theta}$ is the maximum likelihood parameter estimates for the reference model, and $\hat{\gamma}$ is the maximum likelihood parameter estimates for the comparison model. The variance of the likelihood function is given by Vuong as

$\left.\omega=\frac{1}{n} \sum_{j}^{n}{ }^{\prime}{ }^{\prime}[\log \sigma-\operatorname{og} \sigma]+\frac{1}{2}\left[\frac{\varepsilon_{j}}{\sigma_{-}}-\frac{\varepsilon_{j}}{\sigma_{-.}}\right] \backslash{ }^{\ulcorner}-L R_{n}\right]^{-}$ 
where $\varepsilon$ is the residual using the fitted parameters for either the Amihud regression case of the comparison model case. Vuong shows that the likelihood ratio statistic converges to a normal distribution:

Under $\mathrm{H}_{0}: n^{-/ 2} \frac{L R_{n} \theta, \gamma}{\omega} \stackrel{n}{\rightarrow}(0,1)$

The resultant test statistic is stated as

$$
Z=\frac{1}{\sqrt{n}} \frac{L R_{n} \hat{\hat{\theta}}, \hat{\gamma}}{\hat{\omega}}
$$

A one-sided Z-statistic tests whether either of the reference models, in this case being either the Amihud or Turnover measure, is more highly associated with the underlying $\mathrm{S}+\mathrm{C}$ cost than the comparison model(s). The test is directional, given by a positive or negative $\mathrm{Z}$ statistic, indicating which model is more highly associated with the underlying $\mathrm{S}+\mathrm{C}$ cost. A positive and significant Z-statistic indicates that the reference measure is more highly associated with the underlying $\mathrm{S}+\mathrm{C}$ cost than the comparison measure(s). A negative and significant Z-statistic indicates the comparison measure is more highly associated with the underlying $\mathrm{S}+\mathrm{C}$ cost.

Alternatively, the Z-statistic can be obtained from a linear regression if the log ratio is defined at every month $j$ as

$$
m_{j}=\frac{1}{2} \log \left[\frac{\sigma}{\sigma}\right]+\frac{1}{2}\left[\frac{\varepsilon_{j}}{\sigma}-\frac{\varepsilon_{j}}{\sigma}\right]
$$

Vuong states that a useful abstraction of the test statistic in above equation " $\frac{1}{\sqrt{n}} \frac{L R_{n} \hat{\theta}, \hat{\gamma}}{\hat{\omega}}$ is numerically equal to $[(n-1) / n]^{1 / 2}$ times either the usual t-statistic on the constant term in a linear regression of $\mathrm{m}_{\mathrm{j}}$ on only the constant term, or the usual t-statistic on the coefficient of $\mathrm{m}_{\mathrm{j}}$ in a linear regression of one on $\mathrm{m}_{\mathrm{j}}$." Stated another way, the Z-statistic can be obtained by regressing $m_{j}$ on unity and multiplying the $t$-statistic from this regression by $[(n-1) / n]^{1 / 2}$. This procedure involving the running of two subsequent sets of regressions is employed in this paper. 